Research Article

\title{
Safety Analysis of the Running Train under Earthquake Dynamic Disturbance
}

\author{
Mingfei Li and Junwei Liu \\ School of Civil Engineering, Qingdao University of Technology, Qingdao, Shandong 266033, China \\ Correspondence should be addressed to Junwei Liu; liujunwei@qut.edu.cn
}

Received 17 December 2020; Revised 3 January 2021; Accepted 6 January 2021; Published 19 January 2021

Academic Editor: Guangchao Zhang

Copyright ( $\odot 2021$ Mingfei Li and Junwei Liu. This is an open access article distributed under the Creative Commons Attribution License, which permits unrestricted use, distribution, and reproduction in any medium, provided the original work is properly cited.

\begin{abstract}
Focusing on the safe operation of rail transit during earthquakes, the finite element method is used to construct a wheel-tracksubgrade dynamics model in this study. Through spring-damper units, the relationship between the rail and the track slab and the connection between the track slab and the subgrade are established. A method for establishing a viscoelastic artificial boundary is proposed. Four seismic waves-the Tianjin wave, the El Centro wave, the Taft wave, and the Qian'an wave-are selected as the seismic input waveforms, and only the impact of the lateral ground motion on the wheel-track-subgrade system is considered. In this paper, the ground motion problem is transformed into a wave source problem, the seismic input is transformed into an equivalent load acting on the artificial boundary, and the wave input of the viscoelastic artificial boundary is realized. The normalization method is used to process the seismic waves, and a method that converts the input of the seismic waves into equivalent loads is proposed. The changing laws of different dynamic response indexes under the influence of the four waveforms are studied. Under the action of the Tianjin wave, the wheel-rail dynamic response is very violent near the acceleration peak, whereas, after the peak, all dynamic response indexes are within a safe range. Under the effect of the El Centro wave, the collision between the wheel and the track is relatively violent, and the train is already in a dangerous state. Under the action of the Taft wave, due to the sudden action of the peak ground motion acceleration, the displacement between the wheel and the track increases instantaneously, causing the train to derail. Under the action of the Qian'an wave, the force between the wheel and rail changes approximately linearly with respect to the frequency of the ground motion, and all dynamic response indexes are within a safe range. The vibration intensity of the four seismic waves is amplified by an intensity expansion factor. Except for the Tianjin wave, the amplified seismic wave has a greater impact on safe train operations. This paper can provide a reference for research on the running safety of trains under similar dynamic disturbance conditions.
\end{abstract}

\section{Introduction}

To facilitate rapid transportation between large cities, rail transit has developed rapidly in China in recent years. Moreover, increasing attention has been given to disaster prevention in rail transit operations. In particular, China, which is prone to earthquakes, has a large number of rail transit lines in high-intensity earthquake areas. Research on rail transit early-warning systems involves a cross-discipline approach that includes rail transit engineering, earthquake resistance and disaster mitigation, earthquake engineering, information transmission, and automatic control. Among them, earthquake resistance and disaster mitigation in rail transit engineering includes two aspects: the safety of the permanent railway infrastructure and the running safety of trains during earthquakes. The first problem is mainly solved through the seismic fortification of railway engineering structures, for which a series of codes and regulations have been formed [1]. However, it is more difficult to solve train running safety problems that arise during earthquakes. In previous earthquakes, there have been many train derailments and subversions that have affected train operations [2]. Some scholars have also carried out dynamic risk assessments [3-6] and tunnel support structure analysis [7, 8]. Rail transit has a high passenger volume and a high operating speed. If a train derails or overturns in an earthquake, it 
will cause substantial loss of life and property. Therefore, it is of great significance to analyze the running safety of trains during earthquakes.

Many scholars have investigated the running safety of trains during earthquakes. Miura et al. [9] summarized and analyzed the track damage caused by an earthquake, which included the geometric characteristics of the track deformation during an earthquake and the damage and derailment of locomotives, passenger trains, and freight trains on different lines in an earthquake. The study asserted that the deformation characteristics of the track mainly depended on the intensity of the earthquake, the distance from the epicenter, and the support conditions of the foundation under the track. They found that the main reason for damage to locomotives in an earthquake is damage to the railway facilities, especially damage to the embankment. Miyamoto et al. [10] established a train-track interaction model that was subjected to an earthquake. The train was modeled according to the multi-rigid-body dynamics theory. The seismic wave input was simulated by applying lateral and vertical sine waves to the support foundation of the rail under each wheel; only the vibration of the rail was considered, and random irregularities in the rail were not considered. Miyamoto et al. [11] also used the same model to study countermeasures to improve the running safety of trains under earthquake conditions. They believed that, to prevent train derailment, the damping force of the lateral shock absorber should be increased as a basic safety countermeasure. Luo et al. [12, 13] ignored the coupling effect of train body roll and yaw and used a simplified dynamic analysis model of a vehicle subjected to an earthquake to analyze the form of train derailment during the earthquake. They noted that when the seismic excitation frequency is low, overturning derailment is prone to occur, whereas when the seismic excitation frequency is high, it is prone to avoid derailment.

There have also been many studies on train-bridge dynamics under the action of earthquakes. Yan et al. [14] established a dynamic interaction model of trains and rigid beam/flexible arch composite bridges under the action of earthquakes. In their study, the earthquakes acted on the trains and bridges by an external excitation, and the motion of each train was described by the vibration equation of a 5degree-freedom system. Their results showed that, in the seismic design of a bridge structure, special attention should be paid to the train-bridge resonance effect and the vehicle running stability, and the frequency of the bridge pier should not come close to the main resonant frequency of the beam or the train. In the dynamic analysis model of a train-bridge system under the action of earthquakes, Zhang et al. [15] further considered the five degrees of freedom of the frame-lateral, vertical, roll, pitch, and yaw-and analyzed the effect of the train passing through a multispan simply supported beam bridge under the action of an earthquake. Instead of using an external excitation to apply the earthquake action on trains and bridges, Xia et al. [16] used the mass method to make the degrees of freedom of the bridge support nodes meet the acceleration boundary conditions and realize the input of ground motions. Furthermore, they analyzed a train crossing a bridge under the action of an earthquake.
In terms of numerical calculations, many scholars have used finite element methods to build train-track models. Chen [17] established a finite element model of a roadbed in ANSYS using three-dimensional solid elements, simulated one-way and two-way driving of a train by applying moving loads, and analyzed the changes in the displacement and stress of the roadbed. Nie [18] used ANSYS to model a train as a rigid body with multiple degrees of freedom, wherein the rail was meshed with beam elements, and the sleepers, track beds, and subgrades were meshed with eight-node block elements. Furthermore, they established a finite element model of the track subgrade. They used the separation and iteration method to calculate the dynamic vertical interaction of the vehicle track subgrade and analyzed the dynamic response of the track subgrade.

Gong et al. [19] developed a real-time cosimulation solution that combined ANSYS and MATLAB to investigate train-track-bridge dynamic interactions, through which they aimed to provide an effective and robust method for analyzing and assessing the dynamic responses of running trains and bridges while considering their complex nonlinear behaviors under extreme excitations such as earthquakes and strong winds. Yang et al. [20] investigated the dynamic response of a train-bridge system subjected to earthquakes and established a full three-dimensional finite element model of the train-bridge system. Their results showed that the acceleration responses of a train subjected to an earthquake are much greater than those of a train that is not subjected to an earthquake and that the running safety of a moving train is affected by both the earthquake intensity and the running speed of the train.

Most of the above studies on the running safety of trains under the action of earthquakes start from the perspective of train-bridge dynamics and the running safety of trains on bridges. However, there have been few studies on the safety of trains on underground subgrades under the action of earthquakes. Aiming at the safety problems involved in a wheel-track system on an underground subgrade under the action of earthquakes, this paper proposes a wheel-tracksubgrade dynamic model to study the influence of different seismic waves on the running safety of trains. According to the wheel-track dynamic response indexes, the running safety of trains is analyzed. The finite element method is used to establish a numerical model of the following wheel-tracksubgrade dynamic analysis under earthquake action. This model is used to study the dynamic response indexes under four seismic waves: the Tianjin wave, the El Centro wave, the Taft wave, and the Qian'an wave. This research can provide a reference for the safe operation of trains under similar conditions.

\section{Finite Element Model for Dynamic Analysis of the Wheel-Track-Subgrade System under Earthquake Action}

The key to studying the interaction of the wheel-tracksubgrade system under the action of earthquakes is to establish a corresponding dynamic analysis model and adopt appropriate boundary and vibration input methods. In this 
paper, the finite element method is used to establish a wheeltrack-subgrade finite element model, and a consistent viscoelastic artificial boundary is established around the foundation. First, the selection of element types and their parameters in the wheel-track-subgrade dynamic interaction model is introduced. Then, a detailed analysis is performed on the processing of the boundary conditions of this model. Finally, a wheel-track-subgrade-dynamic interaction model is obtained.

2.1. Wheel-Track-Subgrade Calculation Model. The calculation model is shown in Figure 1; note that the tunnel lining structure is omitted from the calculation model for the convenience of calculation. In the model, the wheelset load, wheels, and wheelsets are simplified as a unified rigid body that is in contact with the rail and experiences lateral and vertical displacement and rotational displacement. A contact unit is built to simulate the interaction between the wheels and the track. Springs are built between the track slabs to simulate fasteners. Moreover, the track slabs and subgrade are built with springs to simulate the mortar layer.

In the wheel-track-subgrade model, a 915-passenger train wheel with an inner diameter of $845 \mathrm{~mm}$, an outer diameter of $915 \mathrm{~mm}$, and a thickness of $145 \mathrm{~mm}$ is used. The wheel dimensions are shown in Figure 2. A standard 60track model with a height of $176 \mathrm{~mm}$, a lower width of $150 \mathrm{~mm}$, an upper width of $73 \mathrm{~mm}$, and a waist thickness of $16.5 \mathrm{~mm}$ is adopted. The detailed dimensions of the track are shown in Figure 3. The distance between the rails is $1435 \mathrm{~mm}$, in accordance with the Code for Design of Railway Earth Structure [21], and the wheelset diameter is $100 \mathrm{~mm}$. The wheelset, wheels, and rail connection are shown in Figure 4. The track slab is laid between the steel rails and has a length of $2 \mathrm{~m}$ and a thickness of $160 \mathrm{~mm}$; note that this is a concrete structure. The subgrade is located on the invert of the tunnel. The boundary conditions are artificial viscoelastic boundary elements. The model has 28563 nodes, 36572 elements, and approximately 60,000 degrees of freedom.

The wheels, wheelset, and rails are made of the same material, so they have the same elastic modulus and Poisson's ratio. The material parameters of each component are shown in Table 1.

The wheels and wheelset use PLANE 183 solid elements and are set as rigid materials, and the rails use BEAM 188 beam elements, which are also rigid structures. The rail is constantly impacted during train operation, and it is regarded as a rigid beam acting on the track plate. Concrete is an orthotropic material. Due to the elastic deformation, plastic deformation, and creep of the subgrade during longterm train operation, SOLID 45 solid elements can accurately simulate such deformation. Therefore, SOLID 45 elements are used for the track slab and the subgrade in this model. The finite element model is shown in Figure 5.

\subsection{Connection of the Wheel-Track-Subgrade Components}

2.2.1. Rail-Wheel Slab-Subgrade Connection. In the finite element model of the wheel-track-subgrade model, the

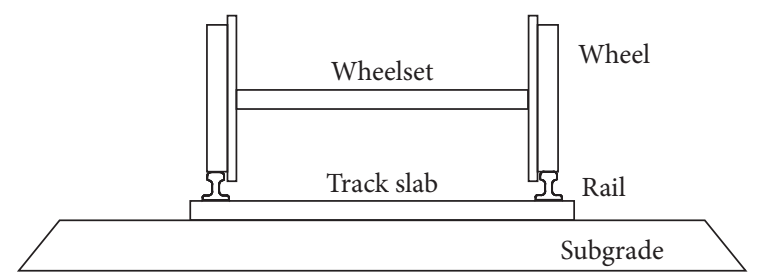

FIGURE 1: Wheel-track-subgrade calculation model.

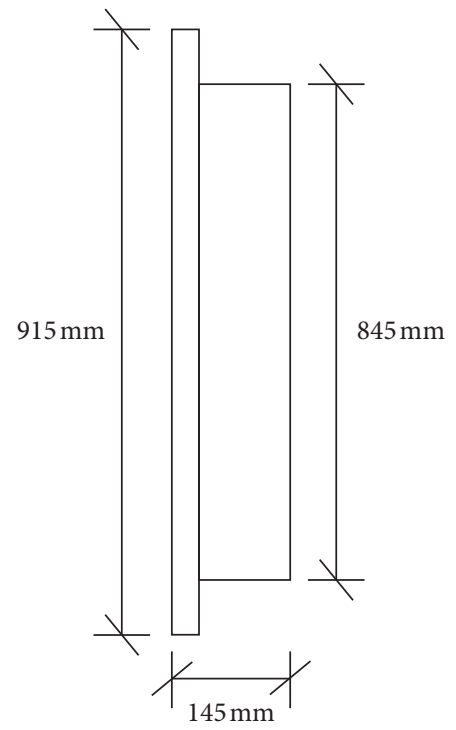

Figure 2: Wheel dimensions.

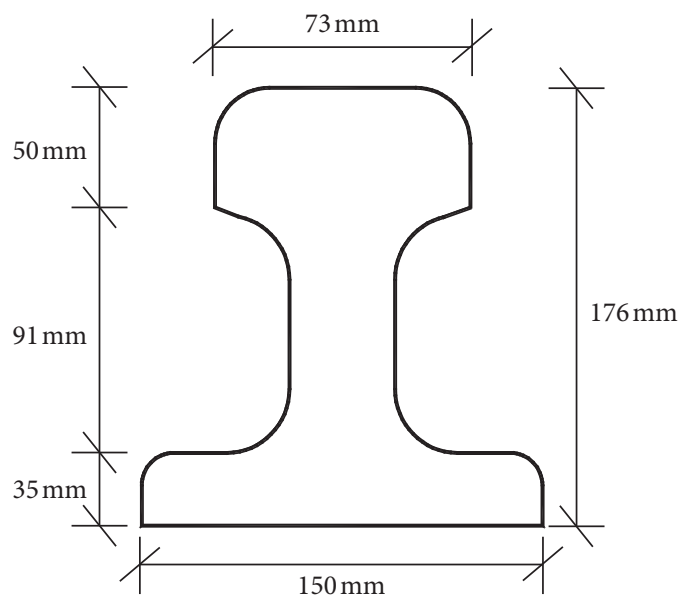

FIgURE 3: Detailed dimensions of the track.

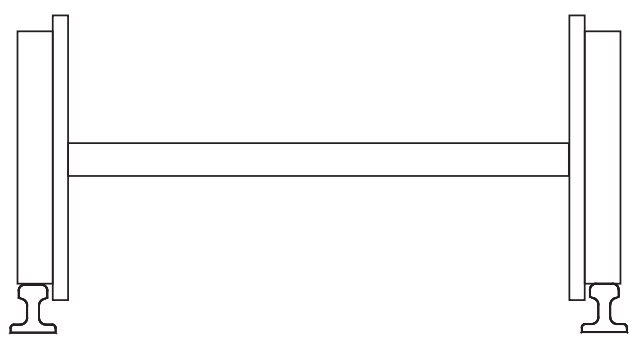

Figure 4: Wheelset-wheel-rail connection. 
TABLE 1: Model material parameters.

\begin{tabular}{|c|c|c|c|c|}
\hline Compo & Parameter & Symbol & Units & Value \\
\hline Wheel & $\begin{array}{l}\text { Elastic modulus } \\
\text { Poisson's ratio } \\
\text { Density }\end{array}$ & $\begin{array}{c}\text { Ex_z } \\
\mathrm{Nu \_ z} \\
\text { Dens_z }\end{array}$ & $\begin{array}{c}\mathrm{Pa} \\
\mathrm{kg} / \mathrm{m}^{3}\end{array}$ & $\begin{array}{c}2.058 \times 10^{11} \\
0.3 \\
1.1 \times 10^{5}\end{array}$ \\
\hline Rail & $\begin{array}{l}\text { Elastic modulus } \\
\text { Poisson's ratio } \\
\text { Density } \\
\end{array}$ & $\begin{array}{c}\text { Ex_z } \\
\text { Nu_z } \\
\text { Dens_z }\end{array}$ & $\begin{array}{c}\mathrm{Pa} \\
\mathrm{kg} / \mathrm{m}^{3}\end{array}$ & $\begin{array}{c}2.058 \times 10^{11} \\
0.3 \\
7850 \\
\end{array}$ \\
\hline Wheelset & $\begin{array}{l}\text { Elastic modulus } \\
\text { Poisson's ratio } \\
\text { Density }\end{array}$ & $\begin{array}{c}\text { Ex_l } \\
\text { Nu_1 } \\
\text { Dens_l }\end{array}$ & $\begin{array}{c}\mathrm{Pa} \\
\mathrm{kg} / \mathrm{m}^{3}\end{array}$ & $\begin{array}{c}2.058 \times 10^{11} \\
0.3 \\
7850\end{array}$ \\
\hline Track slab & $\begin{array}{l}\text { Elastic modulus } \\
\text { Poisson's ratio } \\
\text { Density }\end{array}$ & $\begin{array}{c}\text { Ex_g } \\
\text { Nu_g } \\
\text { Dens_g }\end{array}$ & $\begin{array}{c}\mathrm{Pa} \\
\mathrm{kg} / \mathrm{m}^{3}\end{array}$ & $\begin{array}{c}3 \times 10^{10} \\
0.16 \\
2500\end{array}$ \\
\hline
\end{tabular}

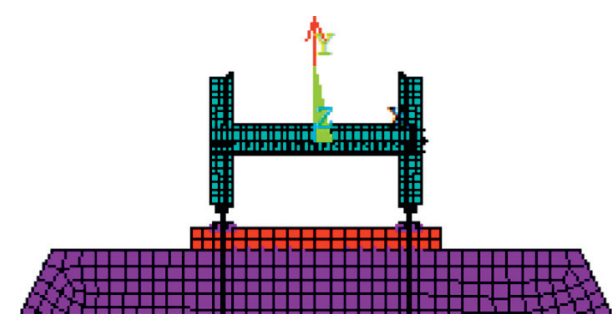

Figure 5: Finite element model for calculation.

connection between the rail and the track slab, and the connection between the track slab and the subgrade are established through spring-damper units. COMBIN 14 elements are selected for the spring-damper unit, which has axial or torsional performance in one-, two-, or three-dimensional applications. The axial spring-damper unit is a one-dimensional tension or compression element, and each node has three degrees of freedom ( $x, y$, and $z$ translation). The spring-damper unit has no mass, so other mass units have been added to the model. The spring-damper unit has a spring constant $k$ and damping coefficients $\mathrm{CV} 1$ and $\mathrm{CV} 2$, and its spring or damping characteristics can be closed in the unit. The spring-damper unit between the rail and the track slab is shown in Figure 6, and its parameter values are shown in Table 2. The spring-damper unit between the track slab and the subgrade is shown in Figure 7, and its parameter values are shown in Table 3.

2.2.2. Wheel-Rail Connection. In the wheel-track-subgrade finite element model, a contact element is established at the wheel-rail contact boundary. The contact position is shown in Figure 8. CONTAC 178 elements are used to represent the contact and sliding between two nodes of any type of element. In this paper, CONTAC 178 elements are used to simulate surface-to-surface contact with point-point contact, and the modified Lagrangian method is used. According to the literature [22], the contact stiffness FKN is $1 \times 10^{6} \mathrm{~N} / \mathrm{m}$, the damping coefficient CV1 is $8 \times 10^{1} \mathrm{~N} / \mathrm{m}$, and the other parameters are default values.

2.3. Viscoelastic Artificial Boundary. There are many ways to establish artificial boundaries, which can be divided into two categories: partial artificial boundaries and all artificial

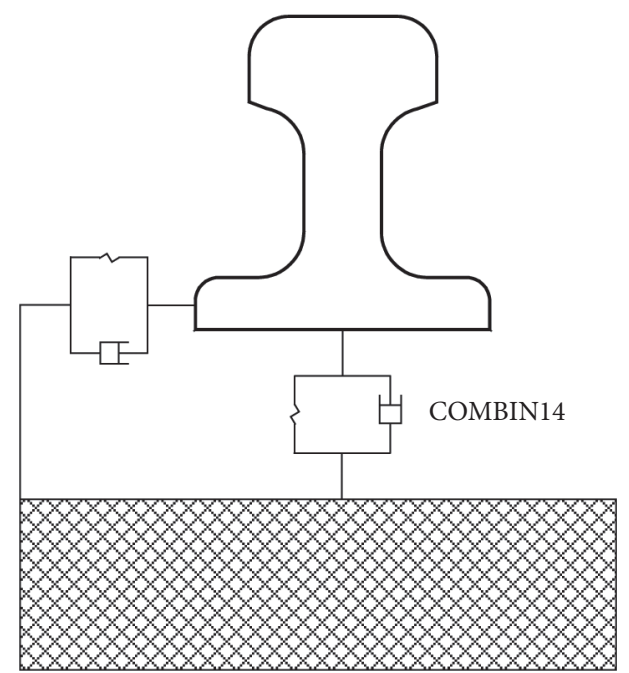

Figure 6: Spring-damper unit between the rail and the track slab.

boundaries. A viscoelastic artificial boundary is a kind of local artificial boundary that overcomes the problem of low-frequency drift caused by viscous boundaries and can simulate the elastic recovery performance of semi-infinite media outside artificial boundaries. A viscoelastic artificial boundary has good low-frequency and high-frequency stability and is easy to apply. A viscoelastic artificial boundary can be equivalent to a continuously distributed parallel spring-damper system. The spring stiffness and damping coefficient in the normal and tangential directions on the artificial boundary are taken according to equations (1) and (2) [23, 24]:

$$
\begin{aligned}
& K_{\mathrm{BN}}=\alpha_{N} \frac{G}{R}, \\
& C_{\mathrm{BN}}=\rho c_{p}, \\
& K_{\mathrm{BT}}=\alpha_{T} \frac{G}{R}, \\
& C_{\mathrm{BT}}=\rho c_{s},
\end{aligned}
$$

where $K_{\mathrm{BN}}$ and $K_{\mathrm{BT}}$ are the normal and tangential spring stiffnesses, respectively; $C_{\mathrm{BN}}$ and $C_{\mathrm{BT}}$ are the normal and tangential damping coefficients, respectively; $R$ is the distance from the wave source to the artificial boundary; $c_{p}$ and $c_{s}$ are the $P$ wave and $S$ wave velocities of the medium, respectively; $G$ is the shear modulus of the medium; $\rho$ is the mass density of the medium; and $\alpha_{N}$ and $\alpha_{T}$ are the correction coefficients of the normal and tangential viscoelastic artificial boundaries, respectively.

The values of $\alpha_{N}$ and $\alpha_{T}$ are taken from Table 4 [25]. For this model, the value of $\alpha_{N}$ is 1 , and the value of $\alpha_{T}$ is 0.5 . In this model, SOLID 45 elements are used for the homogeneous medium and the subgrade area, whereas COMBINE 14 elements are used for the spring-damper unit.

\section{Seismic Wave Input}

3.1. Selection of Seismic Waves. In actual earthquakes, lateral ground motions have a greater impact on the dynamic 
TABLE 2: Spring-damper unit parameters for the rail and the track slab.

\begin{tabular}{lcccc}
\hline Parameter & Normal spring & Normal damping & Tangential spring & Tangential damping \\
\hline Value & $5.9 \times 10^{4}$ & $2.8 \times 10^{2}$ & $8 \times 10^{3}$ & $6.5 \times 10^{1}$ \\
\hline
\end{tabular}

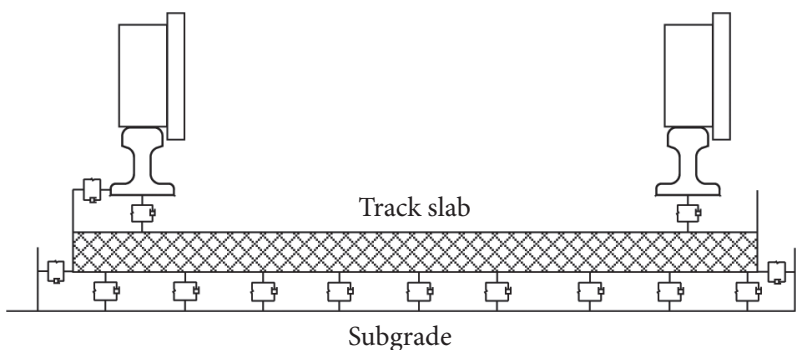

Figure 7: Spring-damper unit between the track slab and the subgrade.

response of trains than vertical ground motions. Therefore, in this paper, only the impact of lateral ground motions on the wheel-track-subgrade system is considered. When selecting seismic waves, the duration of seismic waves, the intensity of ground motions, and the spectral characteristics of seismic waves should be considered. The distance to the epicenter, site conditions, and characteristics of the source will all influence the effects of seismic waves. Many studies use sine waves as seismic waves and add them to the finite element model to study the dynamic response of wheel rails and subgrades. In this article, instead of using sine waves, four seismic waves-the Tianjin wave, the El Centro wave, the Taft wave, and the Qian'an wave-are selected according to the site category. The four types of seismic waves are normalized, and the impact of different ground motion intensities on the running safety of trains is analyzed. The time histories of the four seismic waves are shown in Figures 9-12.

3.2. Seismic Wave Input Method. The ground motion problem is transformed into a wave source problem, the input seismic wave is transformed into an equivalent load acting on the artificial boundary, and the wave input of the viscoelastic artificial boundary is realized. The input problem is simplified to a wave source problem to deal with the wave input. Using the principle of superposition of forces, the equivalent load of the seismic wave is obtained. Assuming that the incident wave field is $u_{0}(x, y, t)$ and the displacement at the artificial boundary is $u\left(x_{B}, y_{B}, t\right)$, the condition for accurately realizing the wave input is that the equivalent load applied on the artificial boundary should make the displacement and stress on the artificial boundary the same as those in the original free field.

$$
\begin{aligned}
& u\left(x_{B}, y_{B}, t\right)=u_{0}\left(x_{B}, y_{B}, t\right), \\
& \tau\left(x_{B}, y_{B}, t\right)=\tau_{0}\left(x_{B}, y_{B}, t\right),
\end{aligned}
$$

where $\tau_{0}$ is the stress generated by the displacement $u_{0}$ in the original continuous medium.
According to this method, the seismic wave input method of the uniform viscoelastic artificial boundary element can be obtained, wherein the following equivalent load is applied on the artificial boundary [26]:

$$
F_{B}(t)=\tau_{0}\left(x_{B}, y_{B}, t\right)+C_{B} \dot{u}_{0}\left(x_{B}, y_{B}, t\right)+K_{B} u_{0}\left(x_{B}, y_{B}, t\right),
$$

where $u_{0}$ is a known displacement field; velocity $\dot{u}_{0}$ and stress $\tau_{0}$ can be obtained from $u_{0}$. Thus, the fluctuating input of the viscoelastic artificial boundary can be realized.

Equation (5) shows that the input load on the surface of the viscoelastic artificial boundary consists of three parts: (a) the stress distribution generated by the free-field vibration on the artificial boundary surface, $(b)$ the additional stress generated by the damper element caused by the velocity of the node at the equilibrium boundary, and $(c)$ the additional stress generated by the spring element caused by the displacement of the node at the equilibrium boundary. The latter two are mainly used to eliminate the additional influence of the boundary on the input of seismic waves. Therefore, if the influence of the spring-damper unit on the boundary is added to equation (5), only the first part is left, namely, the seismic wave load in the free field [27].

3.3. Normalization of Seismic Waves. The normalization method of seismic waves adjusts the peak acceleration recorded by the actual seismic wave to the peak value needed. The speed and displacement are adjusted accordingly. The specific method is to directly multiply by a scale factor as follows:

$$
\begin{aligned}
& a_{x g}^{\prime}(t)=\frac{A_{\text {max }}^{\prime}}{A_{\text {max }}} a_{x g}(t), \\
& v_{x g}^{\prime}(t)=\frac{A_{\text {max }}^{\prime}}{A_{\text {max }}} v_{x g}(t), \\
& d_{x g}^{\prime}(t)=\frac{A_{\text {max }}^{\prime}}{A_{\text {max }}} d_{x g}(t),
\end{aligned}
$$

where $a_{x g}, v_{x g}$, and $d_{x g}$ are the lateral components of the actual seismic acceleration, velocity, and displacement, respectively; $a_{x g}^{\prime}, v_{x g}^{\prime}$, and $d_{x g}^{\prime}$ are the normalized lateral components of the actual seismic acceleration, velocity, and displacement, respectively; $A_{\max }$ is the acceleration peak value of the lateral component of the actual seismic wave; and $A^{\prime}{ }_{\max }$ is the peak lateral acceleration required for analysis.

The corresponding relationship between different seismic fortification intensities of railway projects and acceleration peak of seismic waves $A_{g}$ is given in the Code for Seismic Design of Railway Engineering [1], as shown in Table 5. When analyzing the impact of seismic wave 
TABle 3: Spring-damper unit parameters for the track slab and the subgrade.

\begin{tabular}{lcccc}
\hline Parameter & Normal spring & Normal damping & Tangential spring & Tangential damping \\
\hline Value & $8.5 \times 10^{4}$ & $3.2 \times 10^{2}$ & $1 \times 10^{4}$ & $8.4 \times 10^{1}$ \\
\hline
\end{tabular}

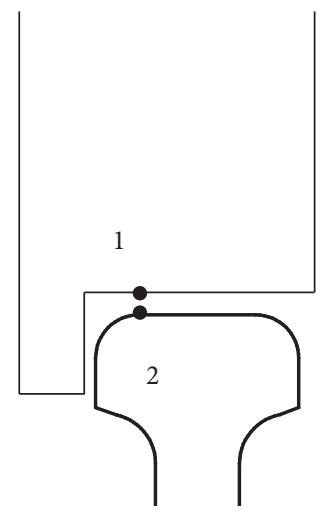

FIGURE 8: Wheel-rail contact.

TABle 4: Value range for the viscoelastic artificial boundary parameters.

\begin{tabular}{lccc}
\hline & Parameter & Value range & $\begin{array}{c}\text { Recommended } \\
\text { coefficient }\end{array}$ \\
\hline Two- & $\alpha_{T}$ & $0.36-0.65$ & $1 / 2$ \\
dimensional & $\alpha_{N}$ & $0.8-1.2$ & $2 / 2$ \\
\hline Three- & $\alpha_{T}$ & $0.5-1.0$ & $2 / 3$ \\
dimensional & $\alpha_{N}$ & $1.0-2.0$ & $4 / 3$ \\
\hline
\end{tabular}

intensity on train safety, the peak value of the actual earthquake must be normalized. According to the method of adjusting the amplitude of the lateral acceleration curve, the specific expansion factor of each seismic wave intensity is shown in Table 6.

3.4. Application of Seismic Waves. According to the seismic wave input method with the viscoelastic boundary proposed in this paper, the normal and tangential time histories of the equivalent load $F_{B}(t)$ for the four seismic waves are shown in Figures 13-16, wherein only the effect of the lateral ground motion is considered.

\section{Influence of Seismic Wave Characteristics on Train Running Safety}

4.1. Influence of Seismic Wave Types on Train Running Safety. Different seismic wave types have different intensity characteristics. In this paper, the Tianjin wave, the El Centro wave, the Taft wave, and the Qian'an wave are added to the wheel-track-subgrade model to calculate the impact on the running safety of trains.

The lateral acceleration, wheel-rail lateral force, wheelrail vertical force, wheel load reduction rate, and derailment coefficient under the action of the four seismic waves are shown in Figures 17-20. The peak values of the dynamic response indexes of the wheel-rail system under the action of the four seismic waves are shown in Table 7.

The train lateral acceleration, wheel-rail lateral force, wheel-rail vertical force, wheel load reduction rate, and derailment coefficient are different under the action of the four seismic waves. For the Tianjin wave, the wheel-rail dynamic response is extremely violent only near the acceleration peak. After the peak value, the wheel-rail dynamic response gradually becomes flat, and the dynamic response indexes are within a safe range. Under the effect of the El Centro wave, the collision between the wheel and the rail is violent. The wheel-rail vertical force reaches $98.9 \mathrm{kN}$, and the wheel load reduction rate of 0.49 and the derailment coefficient of 0.40 indicate that the train is already in a dangerous state. Under the action of the Taft wave, the value is small at first and then quickly enters the peak area. The dynamic response remains flattened for a period of approximately $11 \mathrm{~s}$ after the peak of the ground motion acceleration; then, the collision continues, and it is extremely regular. A series of phenomena indicate that the train has derailed at $11 \mathrm{~s}$. Although the wheel-rail lateral force $(11.2 \mathrm{kN})$, wheel load reduction rate $(0.28)$, and derailment coefficient $(0.22)$ are all within the safe range, due to the sudden action of the peak acceleration of the seismic wave, the displacement between the wheel and the rail increases instantly. This led to the derailment of the train. Under the influence of the Qian'an wave, it can be seen that the force between the wheel and rail changes approximately linearly with respect to the frequency of the seismic wave, and the indexes are all within a safe range.

4.2. Influence of Seismic Wave Intensities on Train Running Safety. The seismic wave normalization method introduced in the article is used to normalize the Tianjin wave, the El Centro wave, the Taft wave, and the Qian'an wave. The specific expansion factors are shown in Table 8. By applying the normalized seismic wave intensities to the wheel-tracksubgrade model, the dynamic response indexes of the wheel rails under different seismic wave intensities can be obtained, and the influence of seismic wave intensities on train running safety can be analyzed.

Under the action of the Tianjin wave, the lateral acceleration, wheel-rail lateral force, wheel-rail vertical force, wheel load reduction rate, and derailment coefficient change with respect to the change in seismic intensity, as shown in Figure 21.

Under the action of the Tianjin wave, when the seismic intensity is $0.05 \sim 0.15 \mathrm{~g}$, as the seismic intensity increases, the lateral acceleration, wheel-rail lateral force, wheel-rail vertical force, wheel load reduction rate, and derailment coefficient all increase approximately linearly. When the seismic intensity is $0.2 \sim 0.4 \mathrm{~g}$, only the wheel load reduction rate increases approximately linearly, and this increase is 


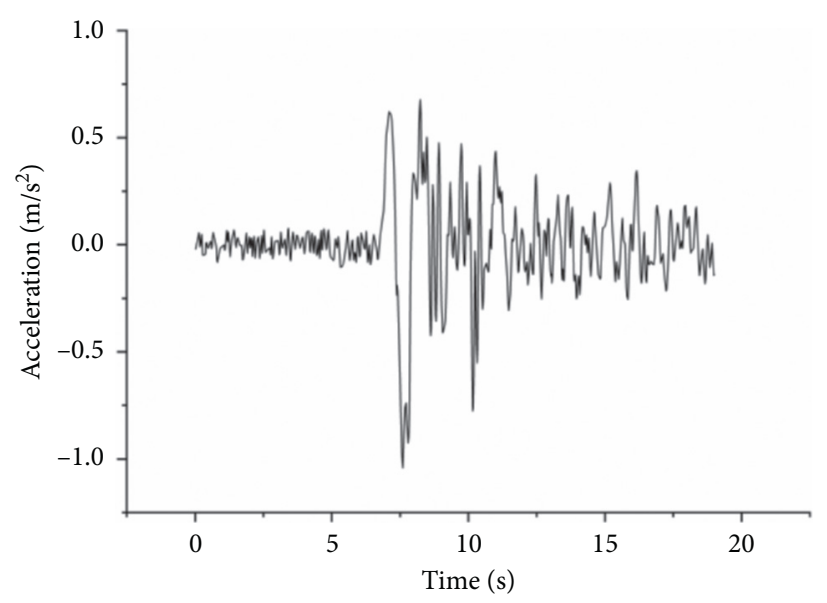

(a)

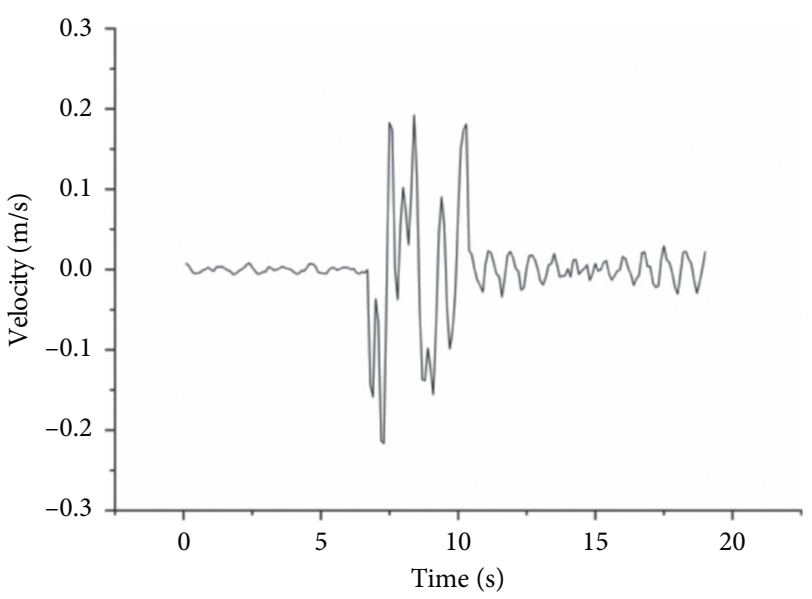

(b)

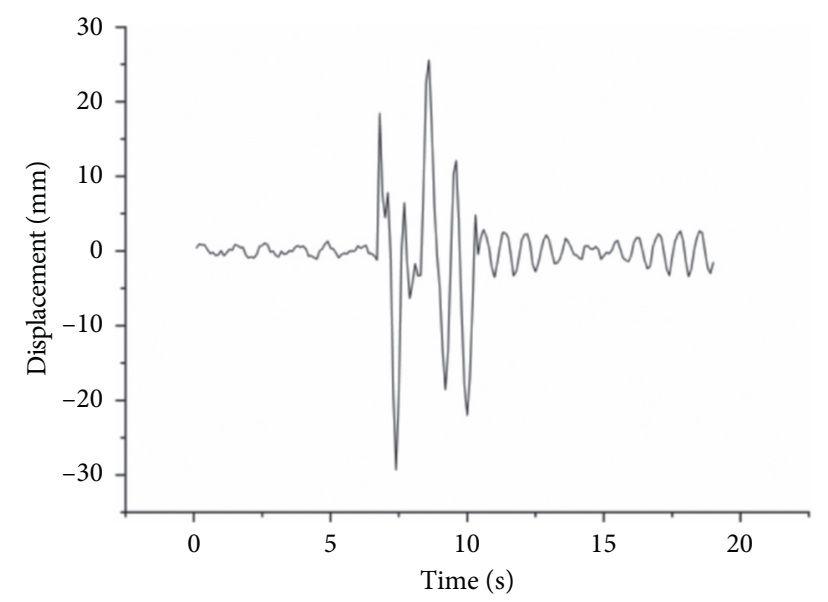

(c)

FIGURE 9: Time history of the Tianjin wave. (a) Lateral acceleration-time curve. (b) Lateral velocity-time curve. (c) Lateral displacement-time curve.

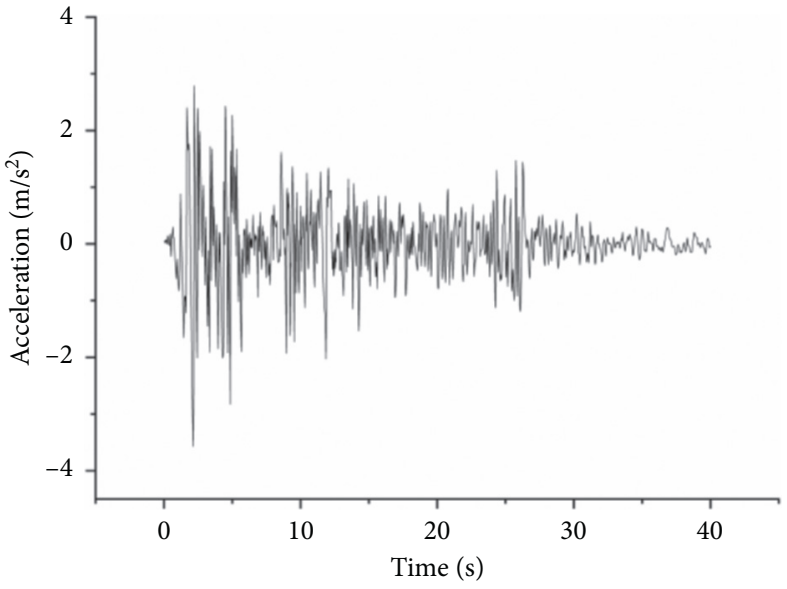

(a)

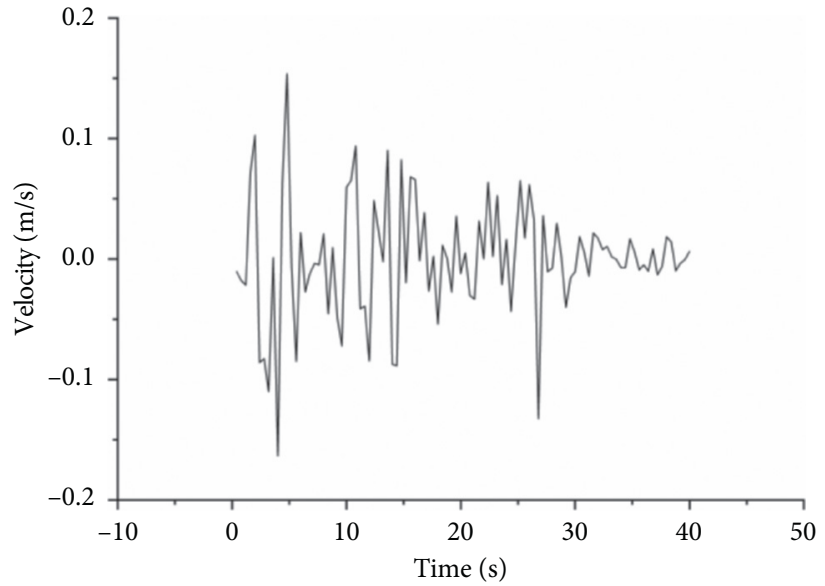

(b)

FIgure 10: Continued. 


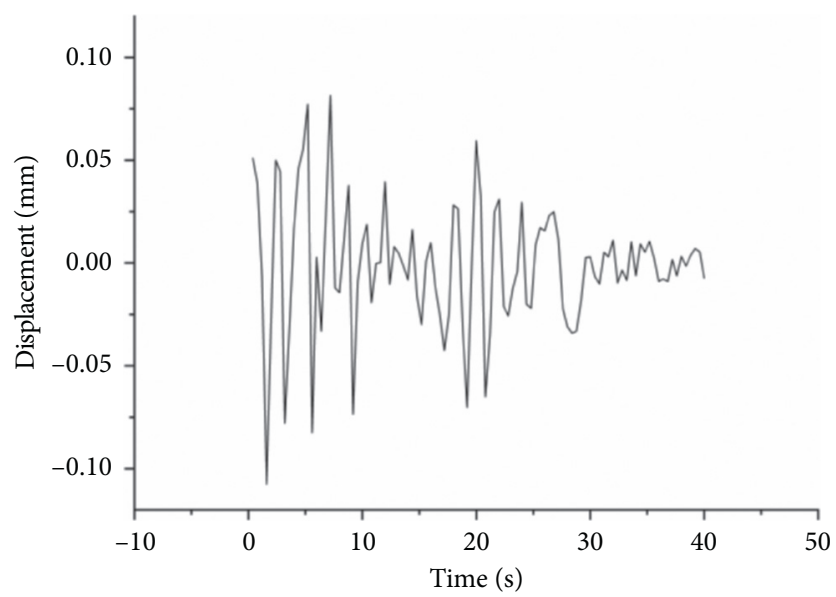

(c)

FIgURE 10: Time history of the El Centro wave. (a) Lateral acceleration-time curve. (b) Lateral velocity-time curve. (c) Lateral displacementtime curve.

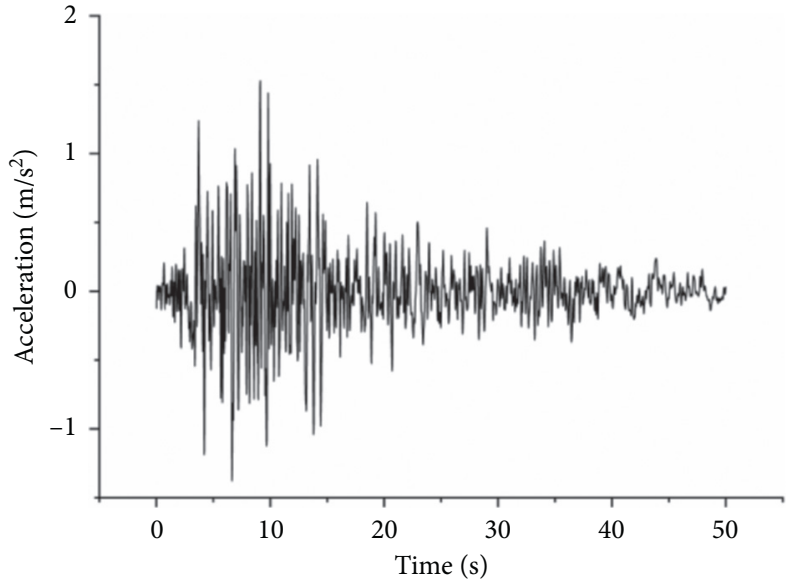

(a)

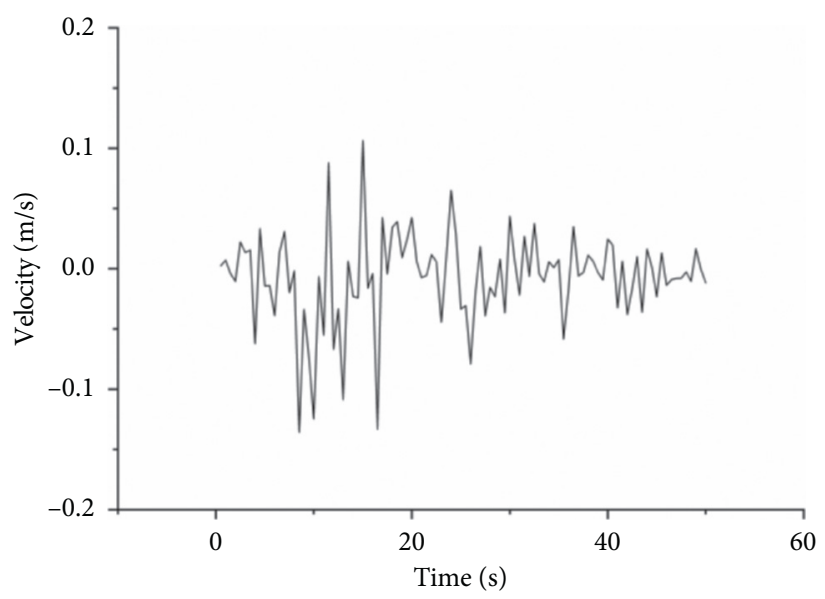

(b)

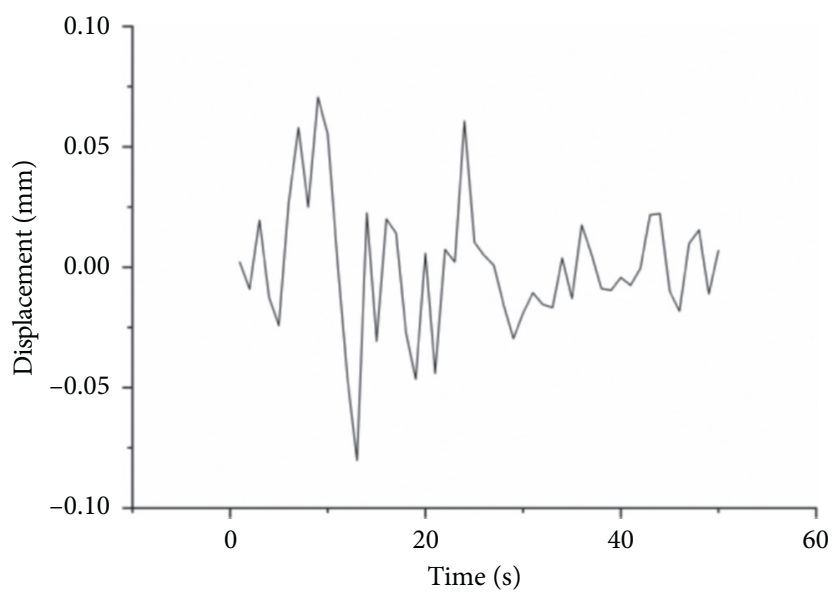

(c)

FIgURE 11: Time history of the Taft wave. (a) Lateral acceleration-time curve. (b) Lateral velocity-time curve. (c) Lateral displacement-time curve. 


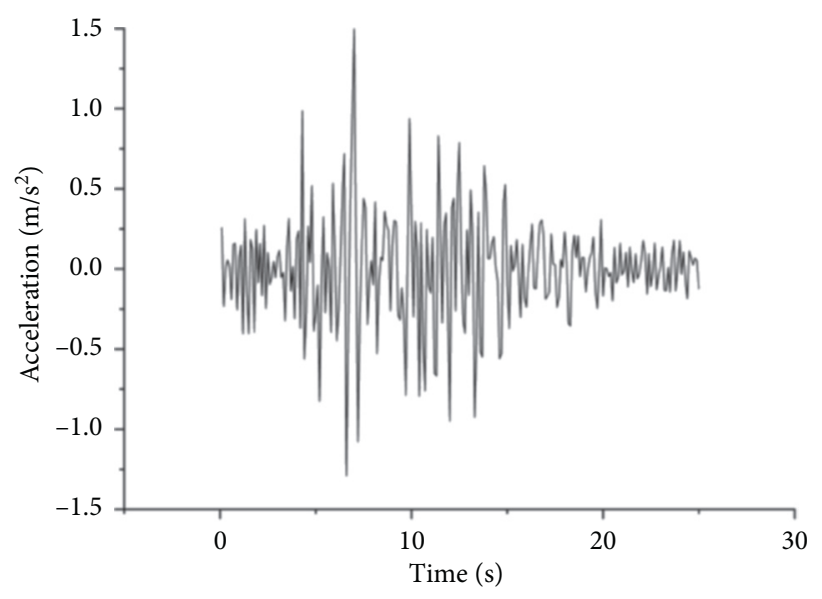

(a)

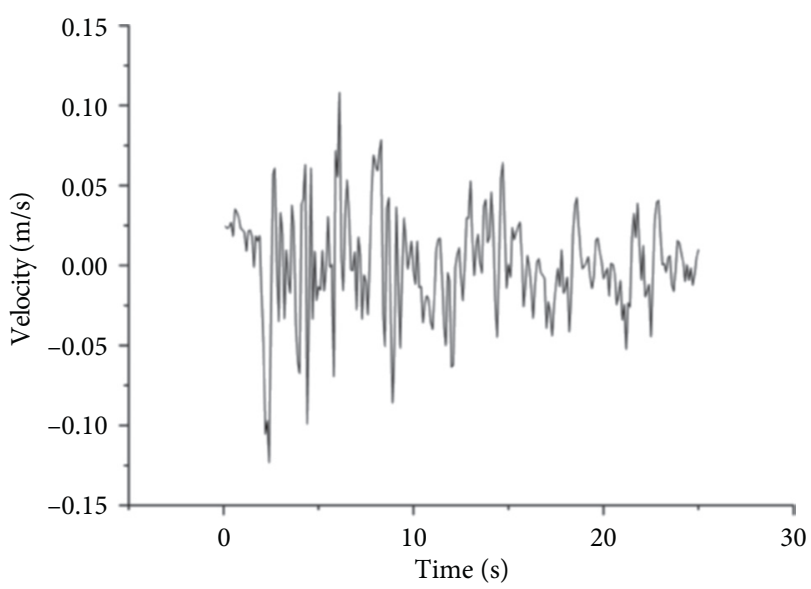

(b)

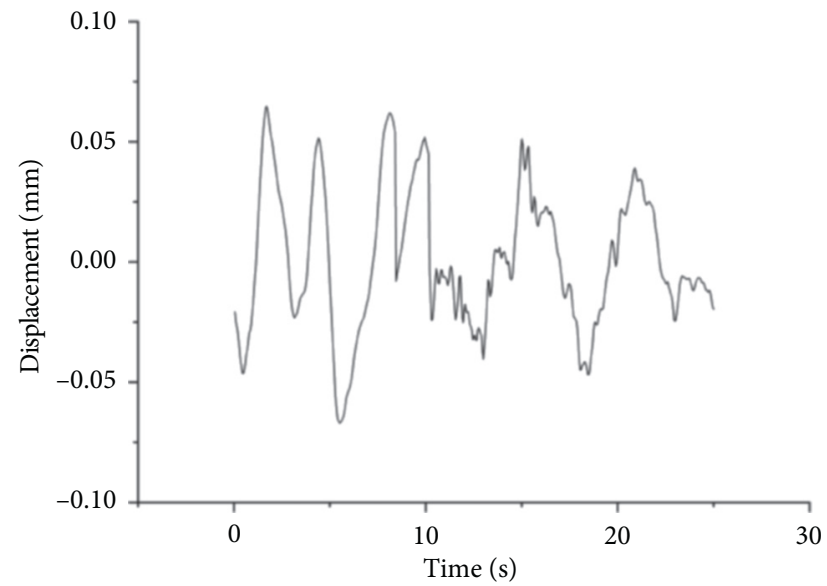

(c)

FIGURE 12: Time history of the Qian'an wave. (a) Lateral acceleration-time curve. (b) Lateral velocity-time curve. (c) Lateral displacementtime curve.

TABLE 5: Seismic fortification intensity and acceleration peak of seismic wave.

\begin{tabular}{lcccccc}
\hline Seismic fortification intensity & 6 & & 7 & 8 & 9 \\
\hline Acceleration peak of seismic wave $A_{g}$ & $0.05 \mathrm{~g}$ & $0.1 \mathrm{~g}$ & $0.15 \mathrm{~g}$ & $0.2 \mathrm{~g}$ & $0.3 \mathrm{~g}$ & $0.4 \mathrm{~g}$ \\
\hline
\end{tabular}

g: gravitational acceleration.

TABLE 6: Expansion factors of seismic waves.

\begin{tabular}{lcccccc}
\hline Seismic wave intensity & $0.05 \mathrm{~g}$ & $0.1 \mathrm{~g}$ & $0.15 \mathrm{~g}$ & $0.2 \mathrm{~g}$ & $0.3 \mathrm{~g}$ & $0.4 \mathrm{~g}$ \\
\hline Expansion factor & 0.3475 & 0.6950 & 1.0426 & 1.3901 & 2.0851 & 2.7801 \\
\hline
\end{tabular}

g: gravitational acceleration.

small. In contrast, the lateral acceleration, wheel-rail lateral force, wheel-rail vertical force, and derailment coefficient all increase rapidly, and the increase is larger than the increase in the wheel load reduction rate.

Under the action of the El Centro wave, the lateral acceleration, wheel-rail lateral force, wheel-rail vertical force, wheel load reduction rate, and derailment coefficient change with respect to changes in the seismic intensities, as shown in Figure 22.
Under the action of the El Centro wave, when the seismic intensity is $0.05 \sim 0.2 \mathrm{~g}$, as the seismic intensity increases, the lateral acceleration, wheel-rail vertical force, and wheel load reduction rate increase approximately linearly. When the seismic intensity is $0.05 \sim 0.15 \mathrm{~g}$, the wheel-rail lateral force and the derailment coefficient exhibit little change. When the seismic intensity is $0.2 \sim 0.4 \mathrm{~g}$, the wheel-rail lateral force and the derailment coefficient increase significantly, indicating that the increase in seismic wave intensity caused 


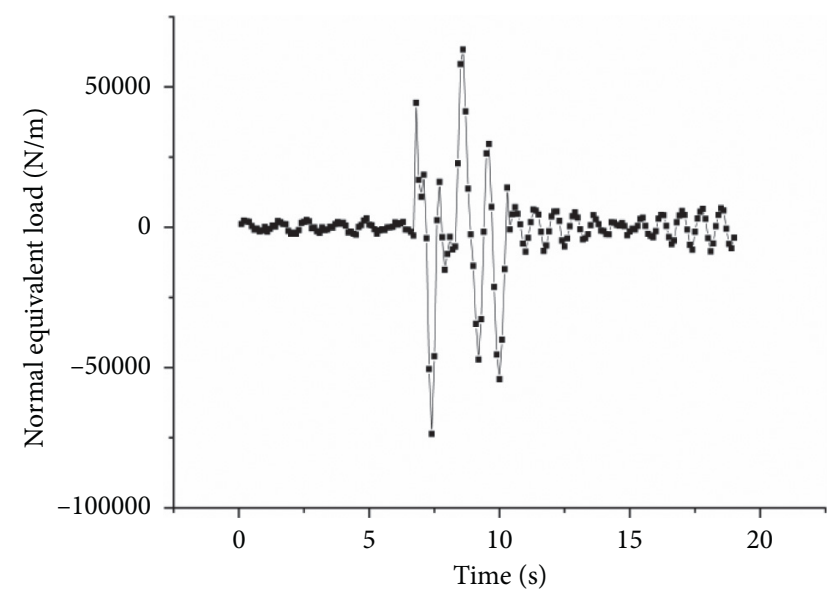

(a)

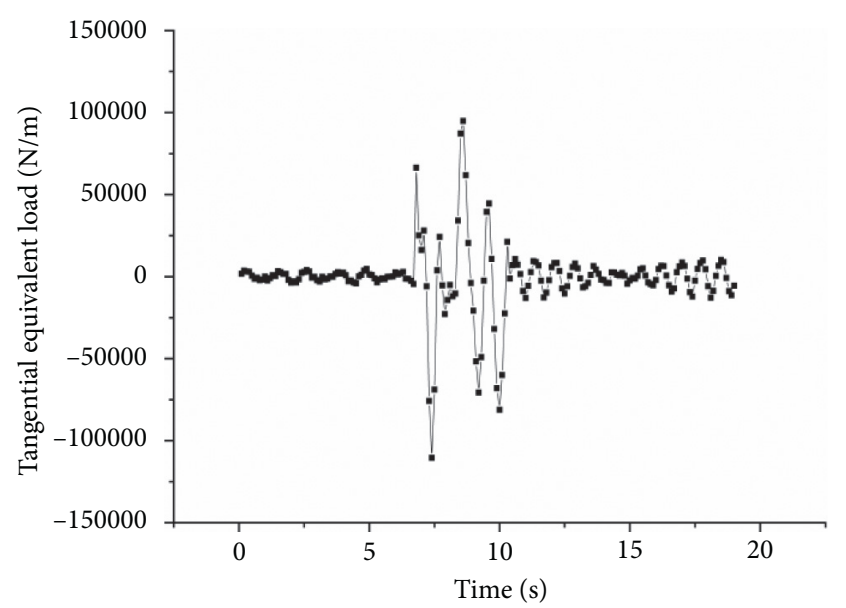

(b)

Figure 13: Boundary equivalent loads of the Tianjin wave. (a) Normal equivalent load $F_{\mathrm{BN}}(t)$-time curve. (b) Tangential equivalent load $F_{\mathrm{BT}}(t)$-time curve.

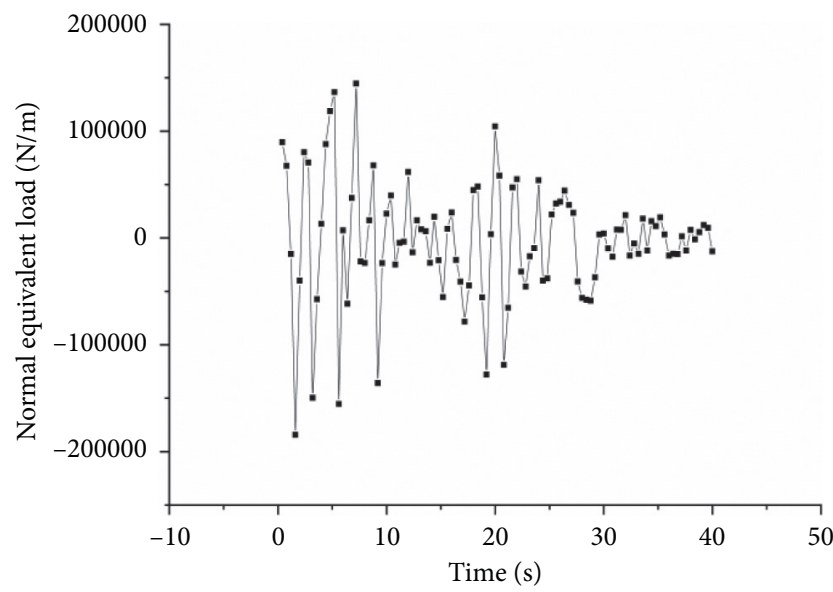

(a)

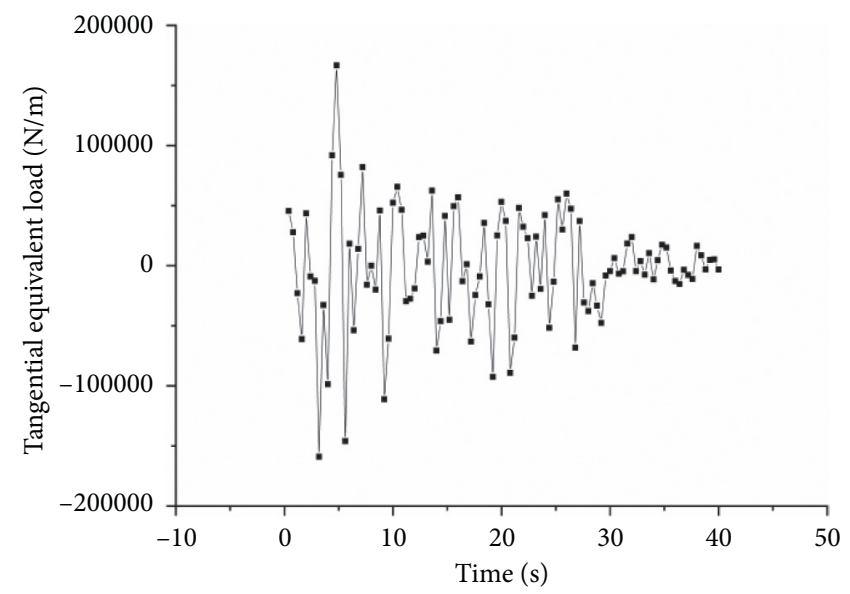

(b)

FIgURE 14: Boundary equivalent loads of the El Centro wave. (a) Normal equivalent load $F_{\mathrm{BN}}(t)$-time curve. (b) Tangential equivalent load $F_{\mathrm{BT}}(t)$-time curve.

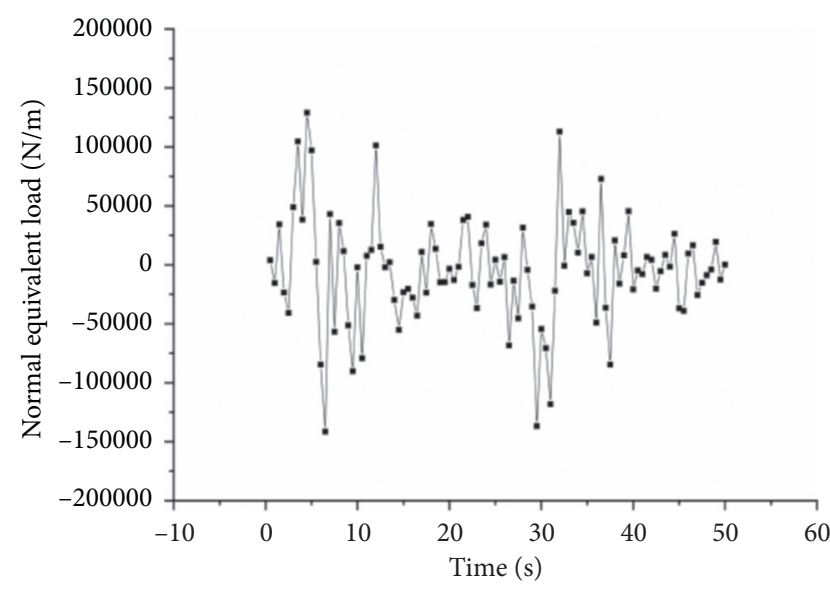

(a)

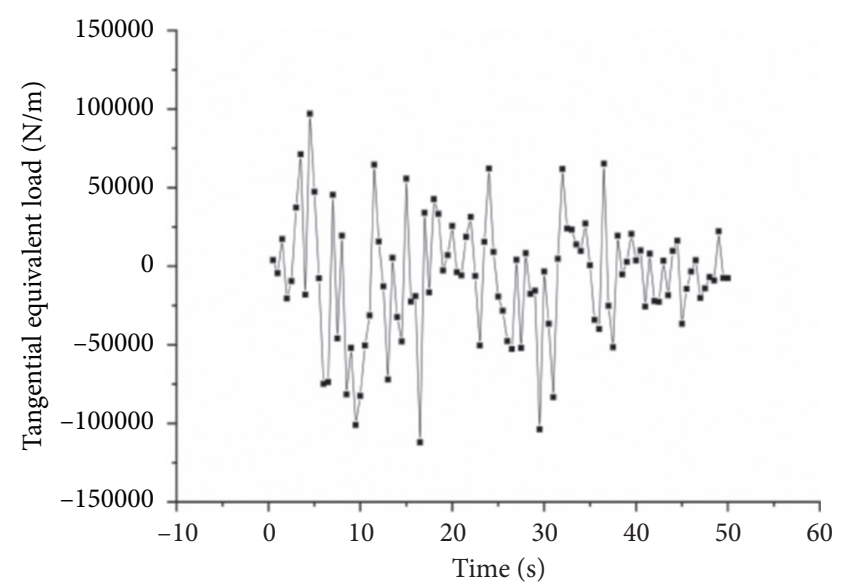

(b)

Figure 15: Boundary equivalent loads of the Taft wave. (a) Normal equivalent load $F_{\mathrm{BN}}(t)$-time curve. (b) Tangential equivalent load $F_{\mathrm{BT}}(t)$-time curve. 


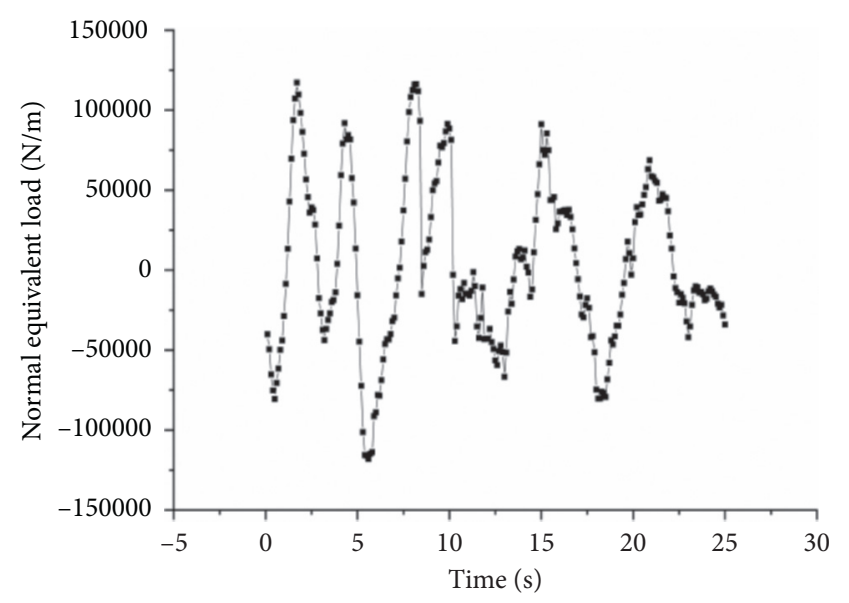

(a)

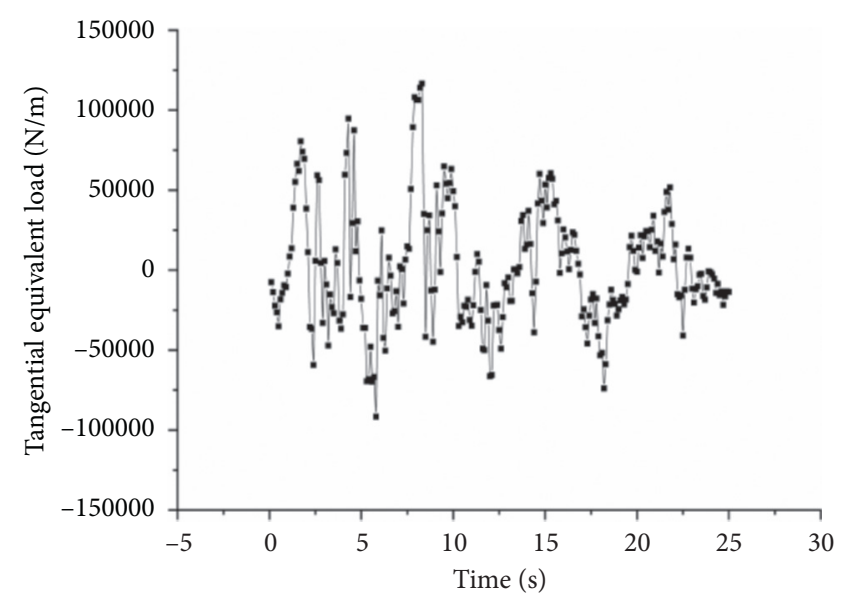

(b)

FIgURE 16: Boundary equivalent loads of the Qian'an wave. (a) Normal equivalent load $F_{\mathrm{BN}}(t)$-time curve. (b) Tangential equivalent load $F_{\mathrm{BT}}(t)$-time curve.

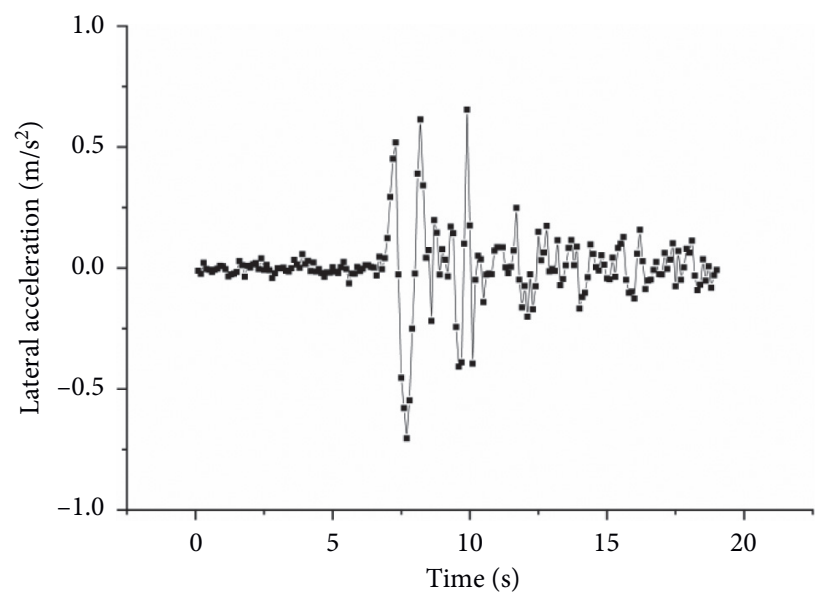

(a)

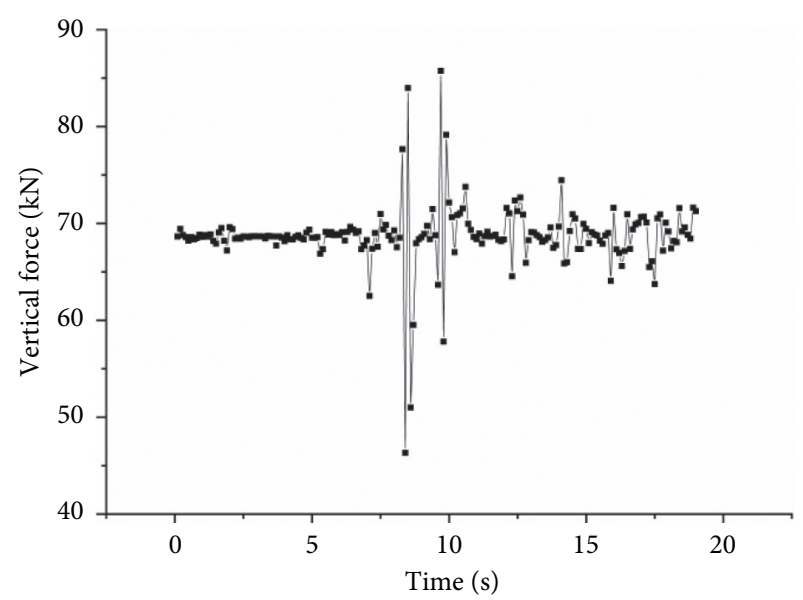

(c)

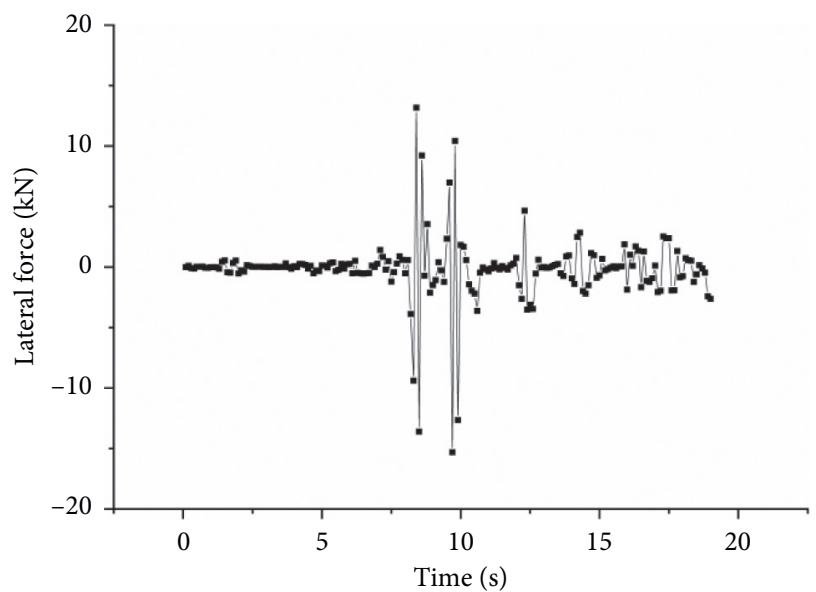

(b)

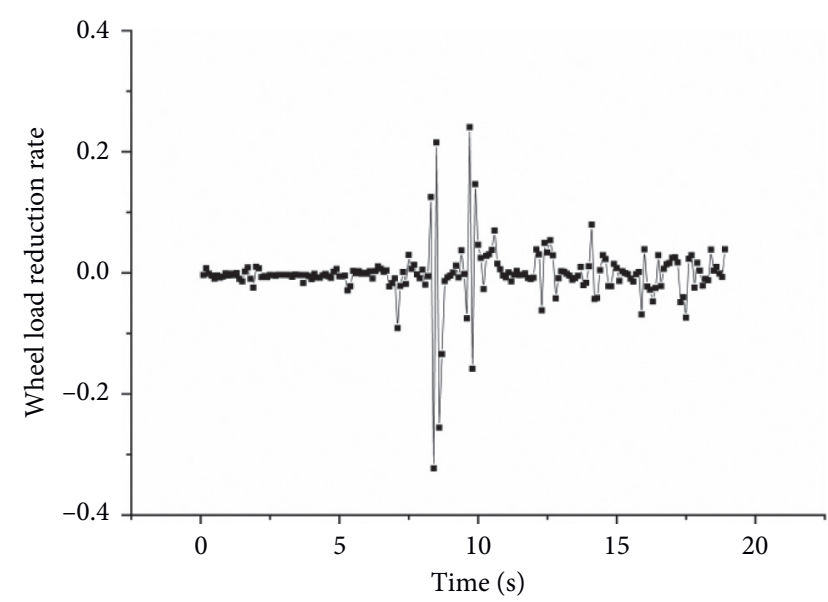

(d)

Figure 17: Continued. 


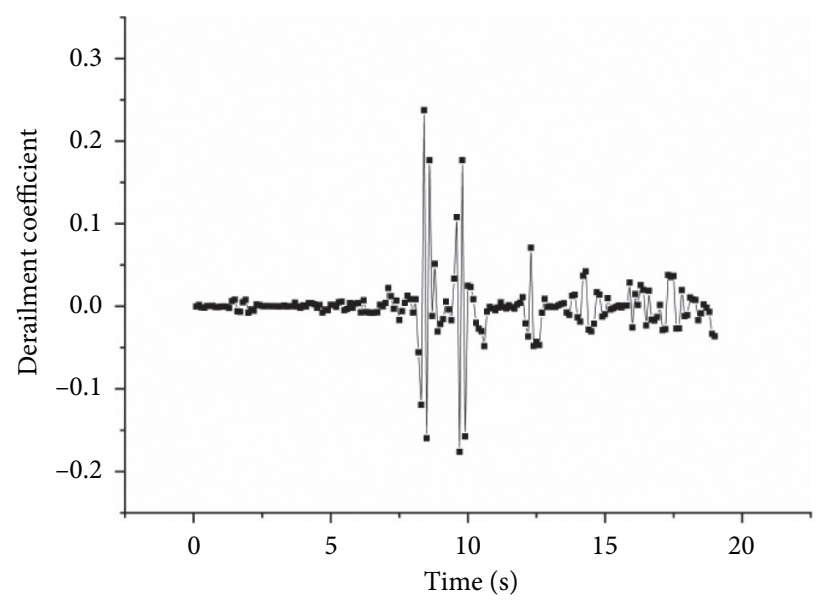

(e)

FIGURE 17: Wheel-track-subgrade time history under the Tianjin wave. (a) Lateral acceleration-time curve of the wheel. (b) Lateral forcetime curve between the wheel and rail. (c) Vertical force-time curve between the wheel and rail. (d) Wheel load reduction rate-time curve. (e) Derailment coefficient-time curve.

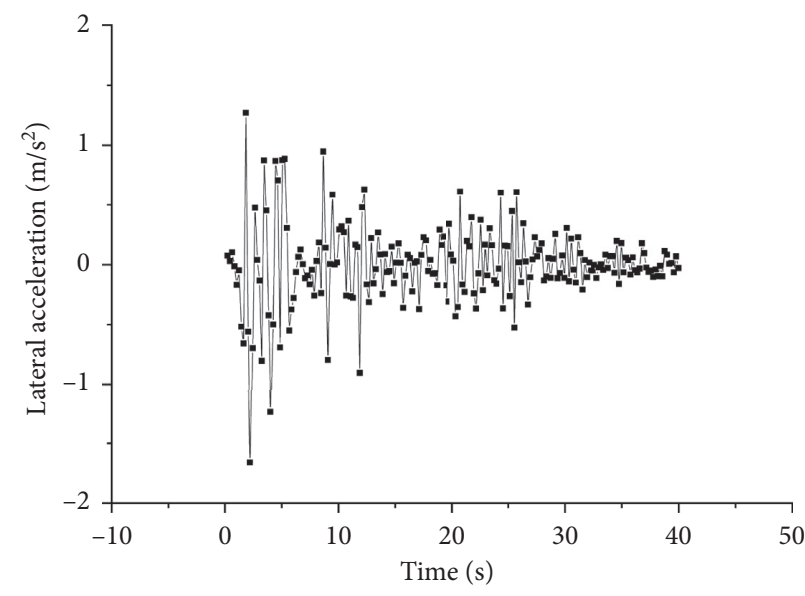

(a)

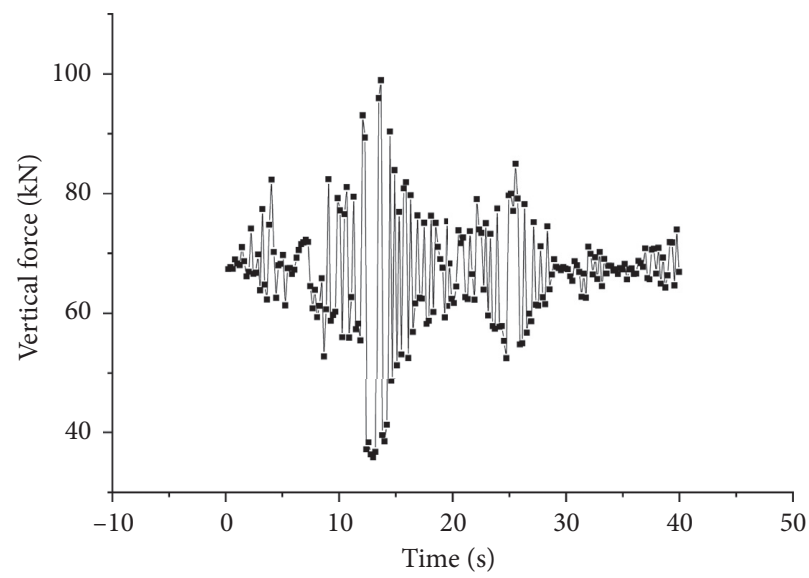

(c)

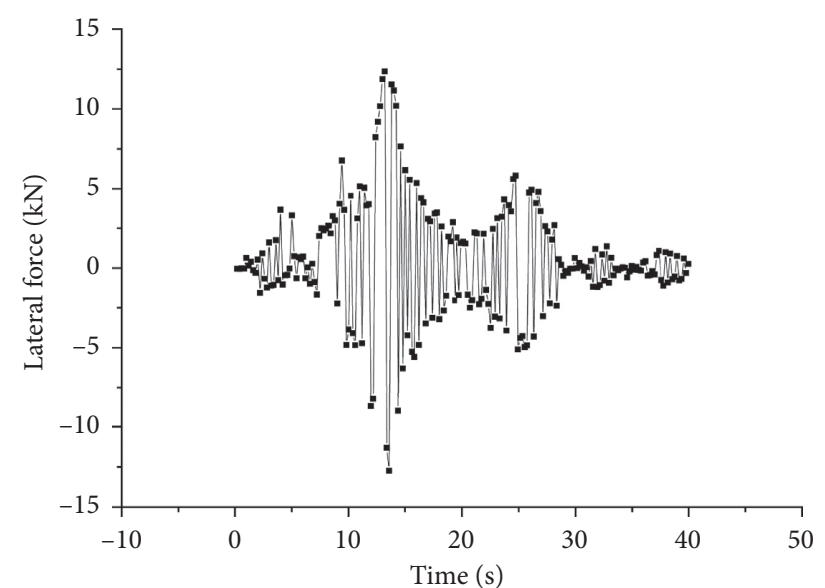

(b)

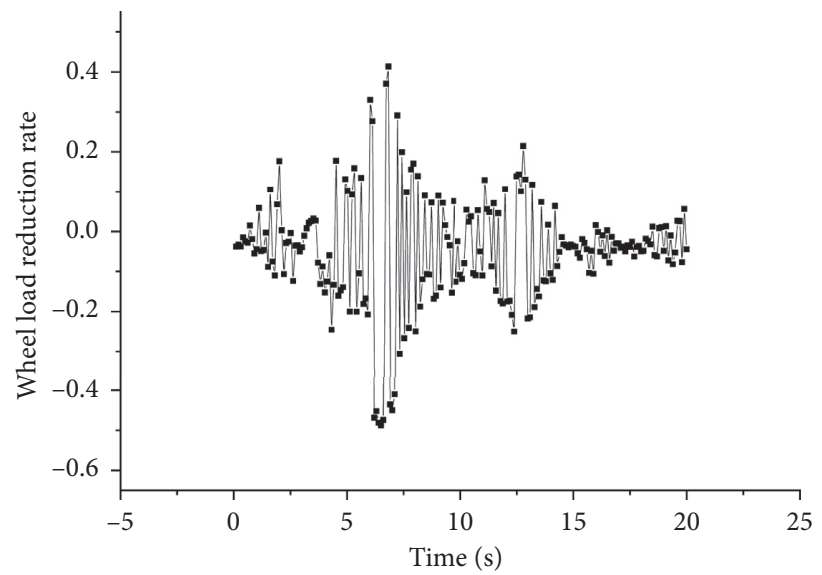

(d)

Figure 18: Continued. 


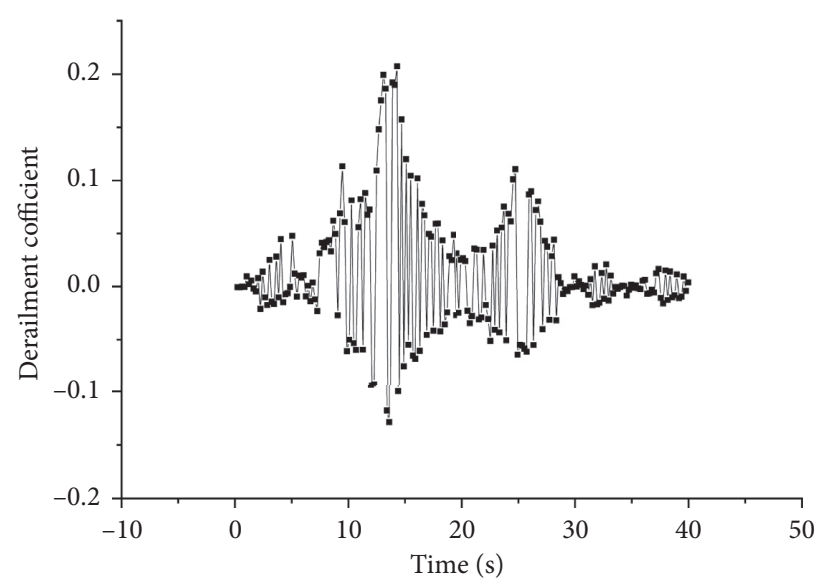

(e)

FiguRE 18: Wheel-track-subgrade time history under the El Centro wave. (a) Lateral acceleration-time curve of the wheel. (b) Lateral forcetime curve between the wheel and rail. (c) Vertical force-time curve between the wheel and rail. (d) Wheel load reduction rate-time curve. (e) Derailment coefficient-time curve.

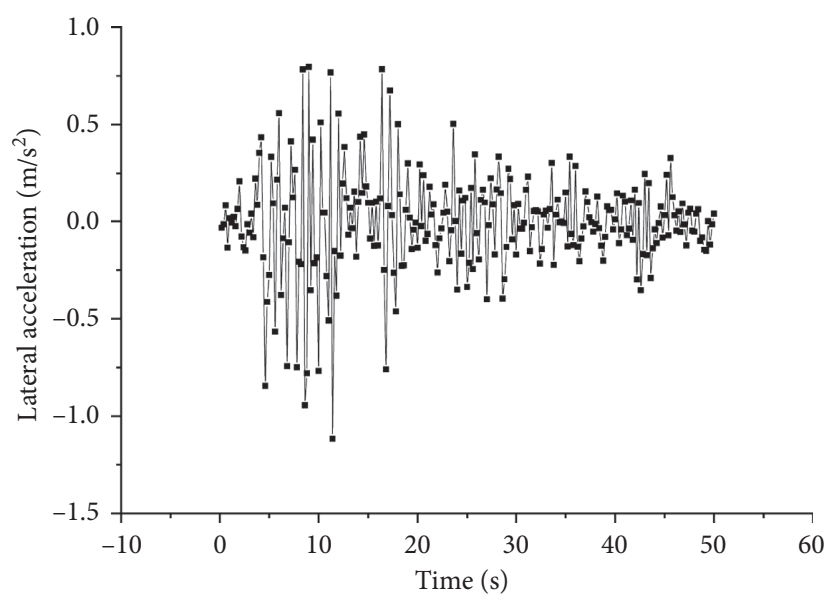

(a)

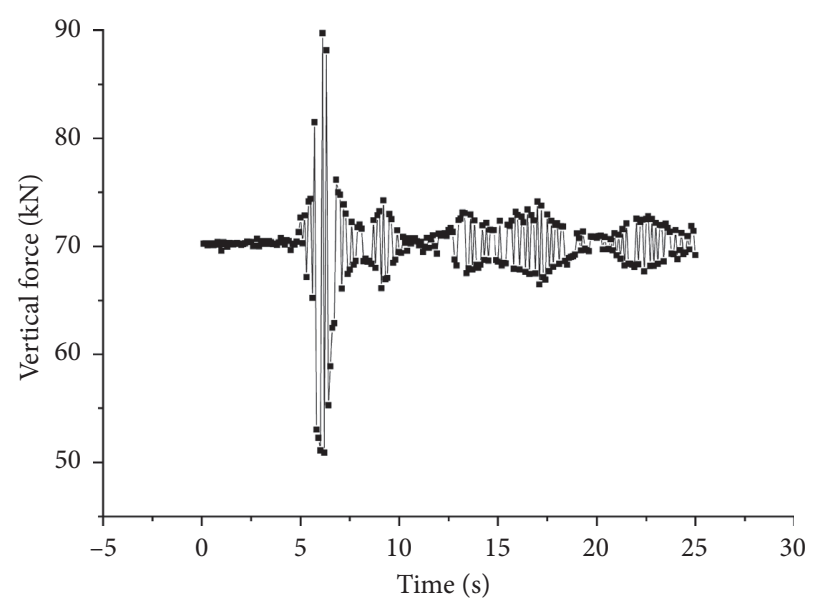

(c)

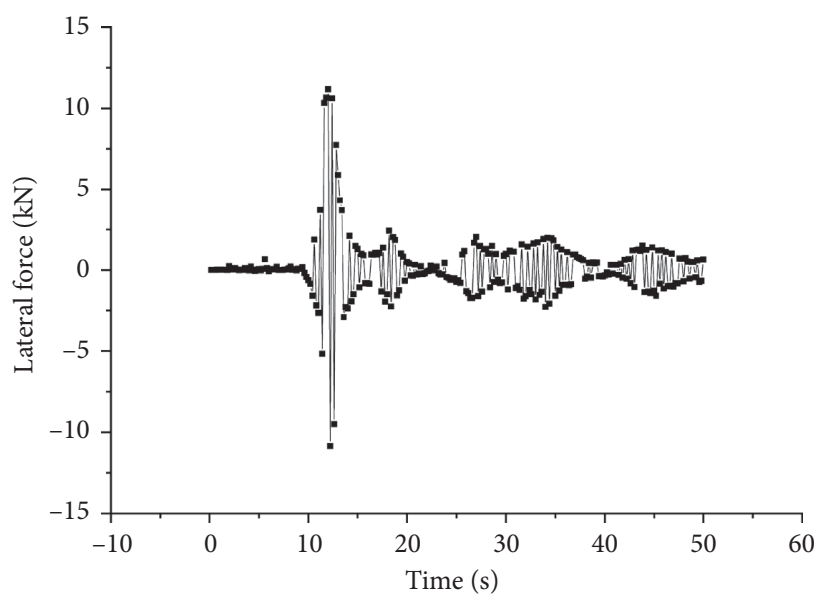

(b)

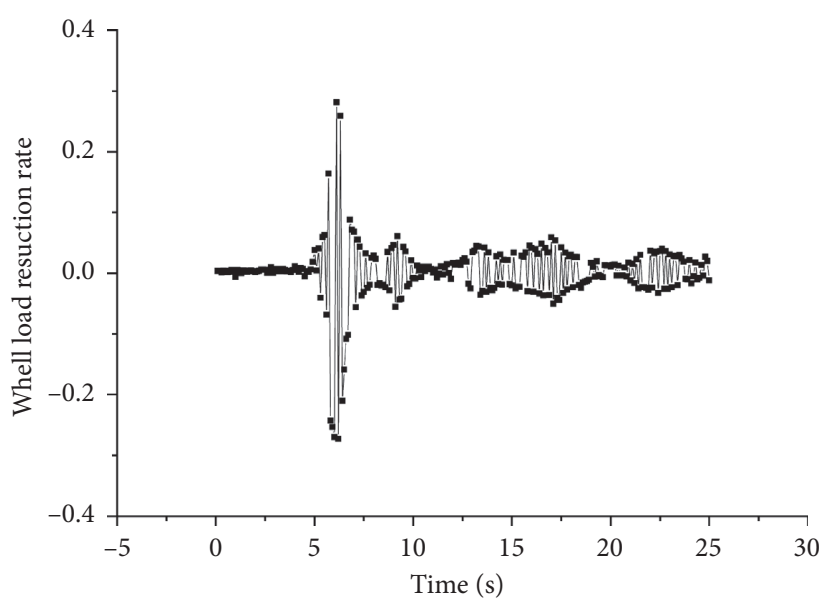

(d)

Figure 19: Continued. 


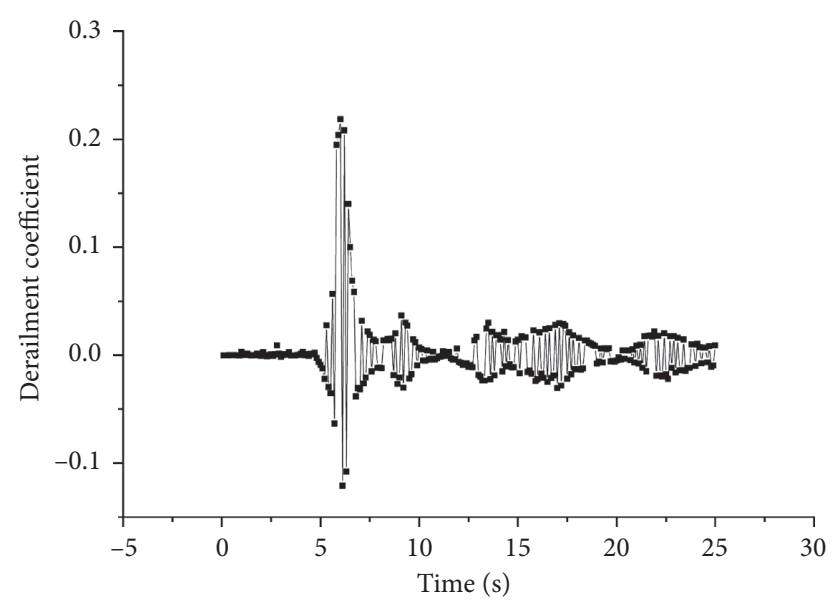

(e)

Figure 19: Wheel-track-subgrade time history under the Taft wave. (a) Lateral acceleration-time curve of the wheel. (b) Lateral force-time curve between the wheel and rail. (c) Vertical force-time curve between the wheel and rail. (d) Wheel load reduction rate-time curve. (e) Derailment coefficient-time curve.

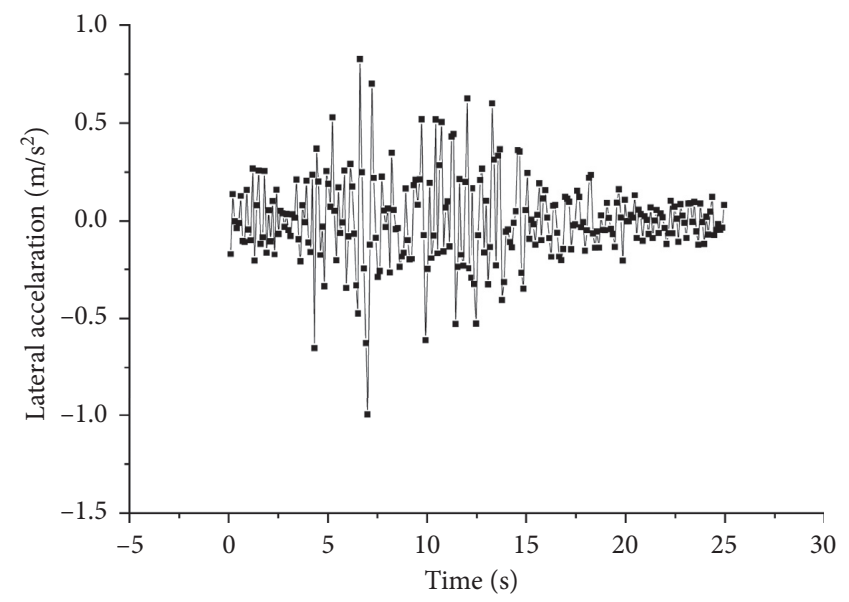

(a)

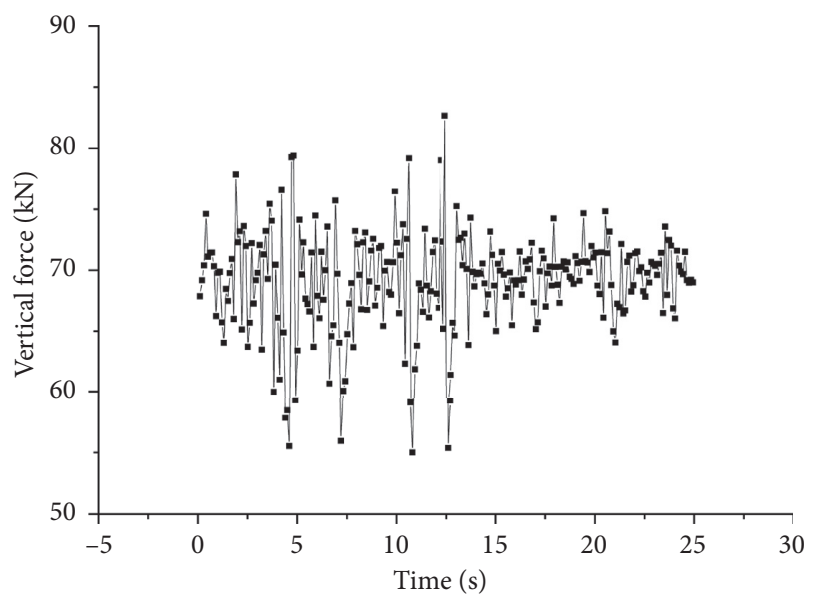

(c)

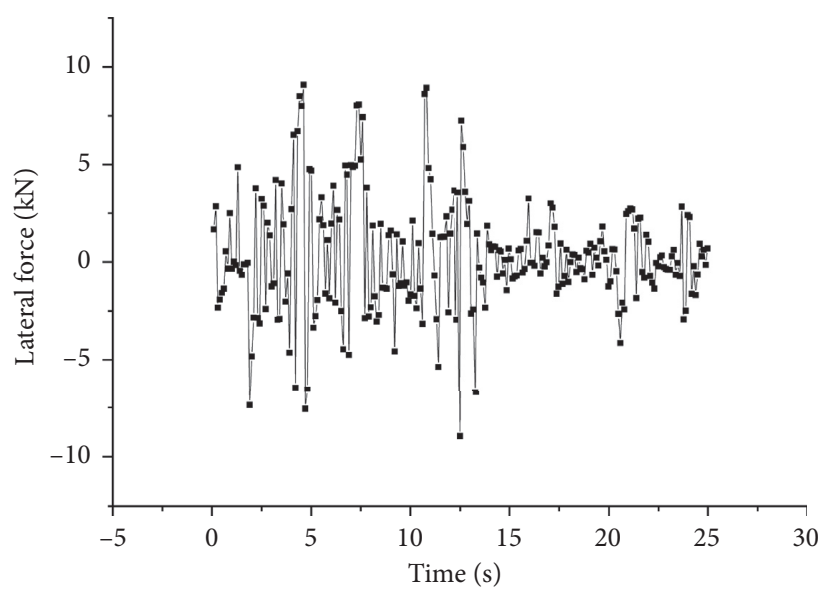

(b)

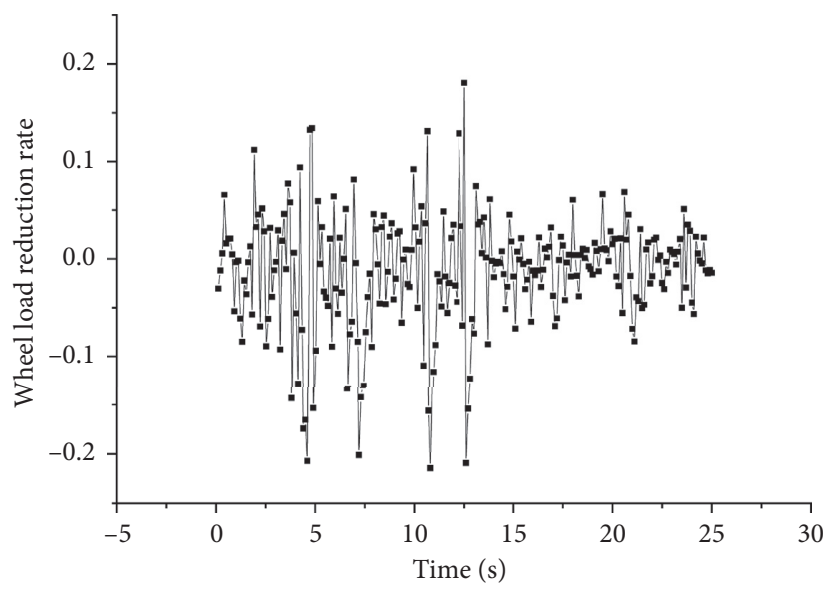

(d)

FIGURE 20: Continued. 


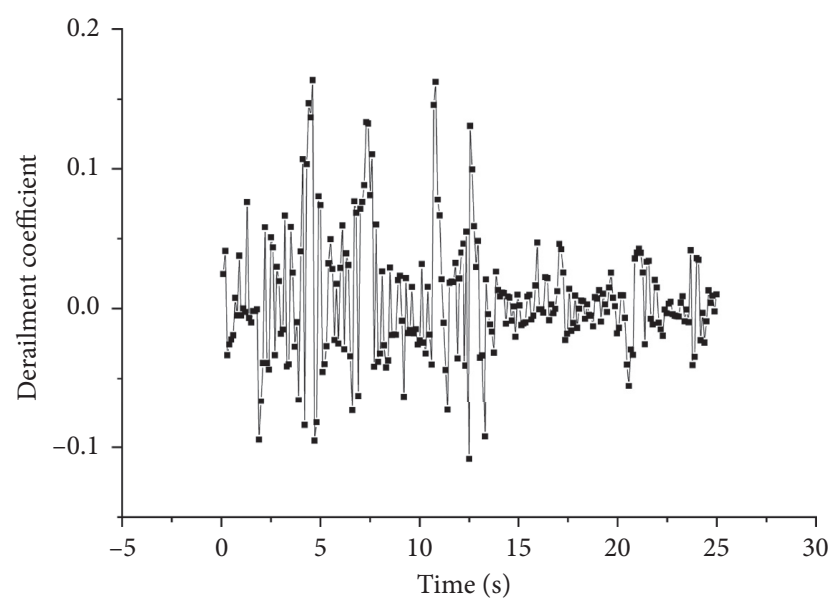

(e)

FiguRE 20: Wheel-track-subgrade time history under the Qian'an wave. (a) Lateral acceleration-time curve of the wheel. (b) Lateral forcetime curve between the wheel and rail. (c) Vertical force-time curve between the wheel and rail. (d) Wheel load reduction rate-time curve. (e) Derailment coefficient-time curve.

TABLE 7: Peak values of the dynamic response indexes of the wheel-rail system.

\begin{tabular}{lccccc}
\hline Peak value & $\begin{array}{c}\text { Train lateral } \\
\text { acceleration }\end{array}$ & $\begin{array}{c}\text { Wheel-rail lateral force } \\
(\mathrm{kN})\end{array}$ & $\begin{array}{c}\text { Wheel-rail vertical force } \\
(\mathrm{kN})\end{array}$ & $\begin{array}{c}\text { Wheel load reduction } \\
\text { rate }\end{array}$ & $\begin{array}{c}\text { Derailment } \\
\text { coefficient }\end{array}$ \\
\hline $\begin{array}{l}\text { Tianjin wave } \\
\text { El Centro }\end{array}$ & $0.70 \mathrm{~m} / \mathrm{s}^{2}$ & 15.3 & 85.7 & 0.32 & 0.23 \\
wave & $1.66 \mathrm{~m} / \mathrm{s}^{2}$ & 12.9 & 98.9 & 0.49 & 0.40 \\
Taft wave & $1.12 \mathrm{~m} / \mathrm{s}^{2}$ & 11.2 & 89.7 & 0.28 & 0.22 \\
Qian'an wave & $1.06 \mathrm{~m} / \mathrm{s}^{2}$ & 9.1 & 82.6 & 0.21 & 0.16 \\
\hline
\end{tabular}

TABLE 8: Expansion factors of the seismic wave intensities.

\begin{tabular}{lcccccc}
\hline Expansion factor & $0.05 \mathrm{~g}$ & $0.1 \mathrm{~g}$ & $0.15 \mathrm{~g}$ & $0.2 \mathrm{~g}$ & $0.3 \mathrm{~g}$ & $0.4 \mathrm{~g}$ \\
\hline Tianjin wave & 0.3475 & 0.6950 & 1.0426 & 1.3901 & 2.0851 & 2.7801 \\
El Centro wave & 0.2941 & 0.5882 & 0.8824 & 1.1765 & 1.7647 & 2.3529 \\
Taft wave & 0.4425 & 0.8850 & 1.3274 & 1.7699 & 2.6549 & 3.5398 \\
Qian'an wave & 0.3333 & 0.6667 & 1.0000 & 1.3333 & 2.0000 & 2.6667 \\
\hline
\end{tabular}

g: gravitational acceleration.

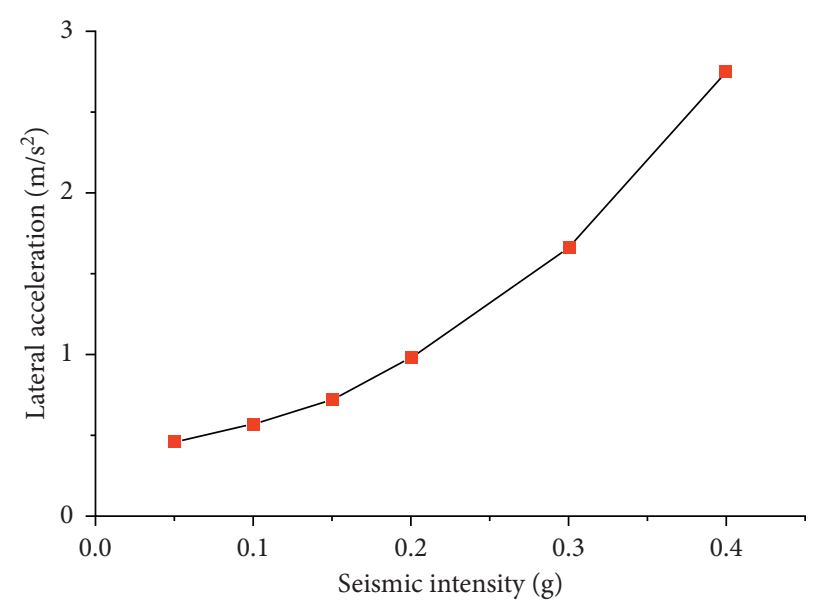

(a)

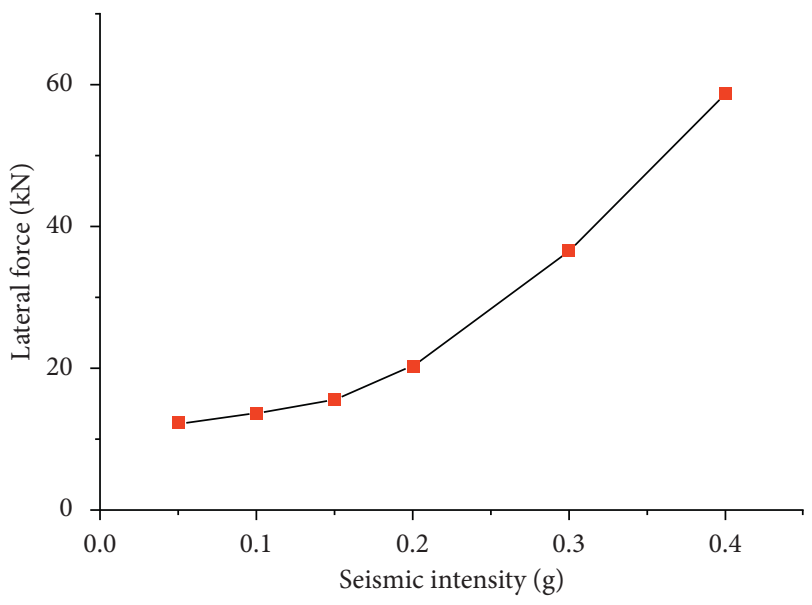

(b)

FIgURE 21: Continued. 


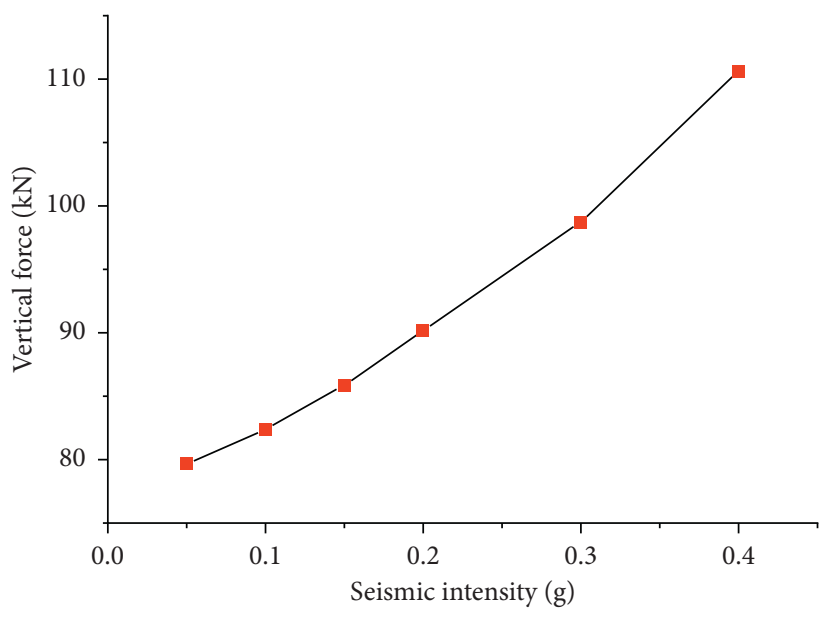

(c)

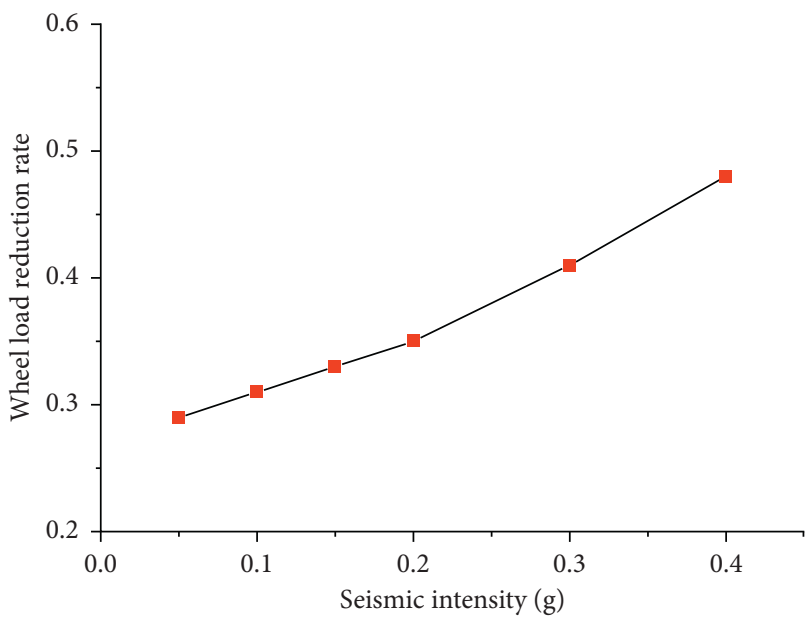

(d)

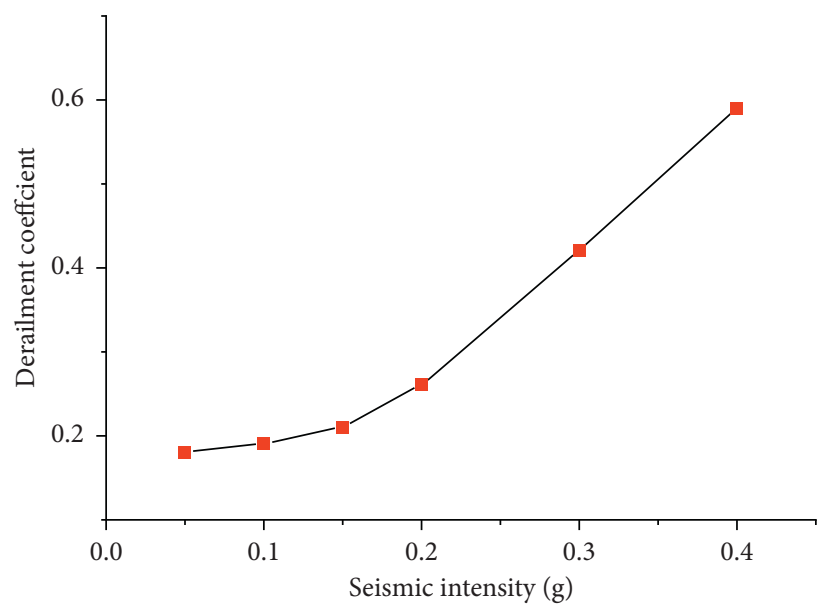

(e)

FIGURE 21: Changes in dynamic response indexes under the Tianjin wave. (a) Changes in lateral acceleration. (b) Changes in lateral force. (c) Changes in vertical force. (d) Changes in wheel load reduction rate. (e) Changes in derailment coefficient.

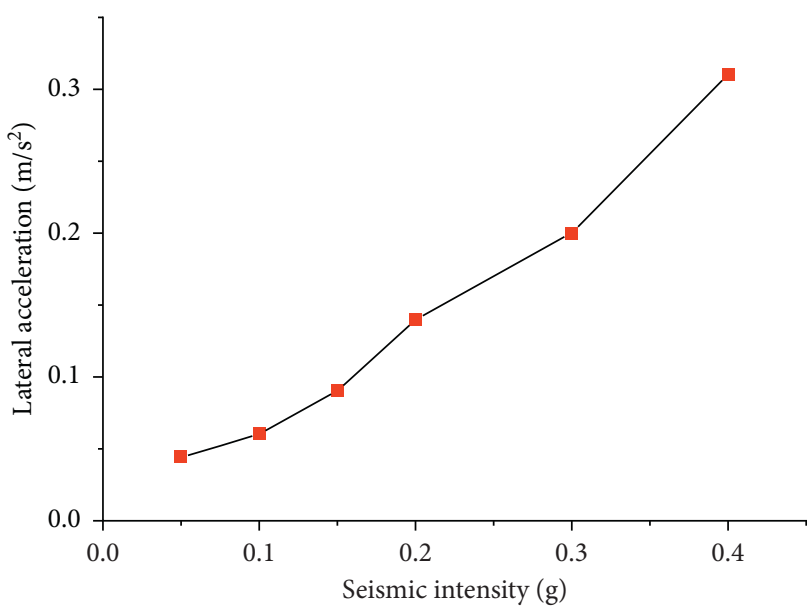

(a)

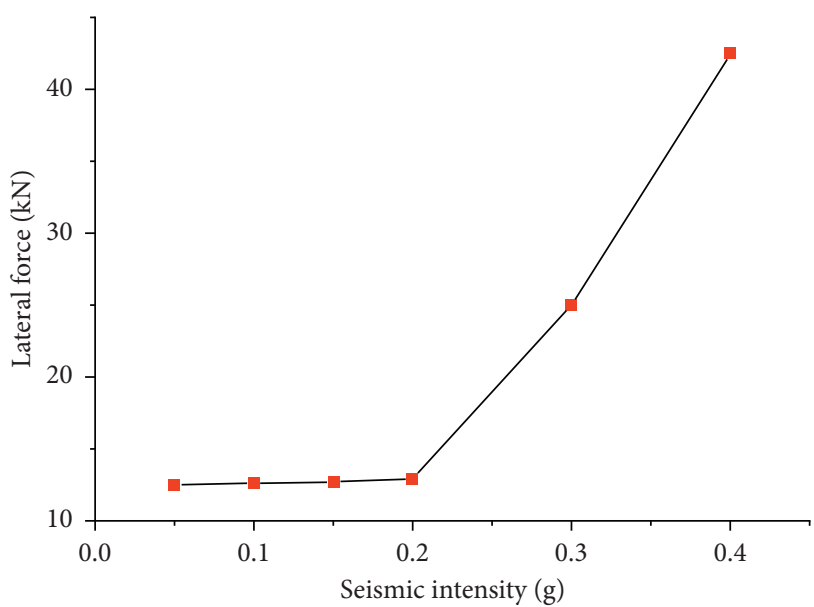

(b)

Figure 22: Continued. 


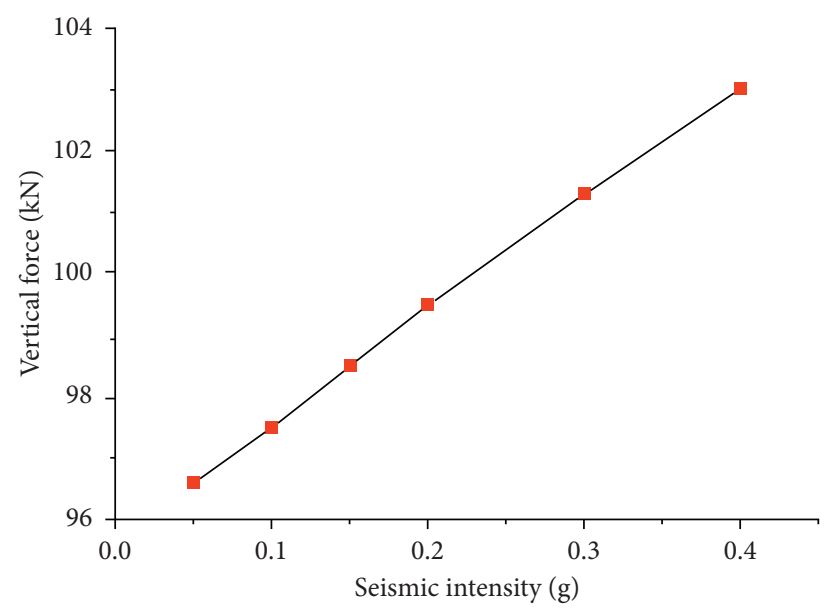

(c)

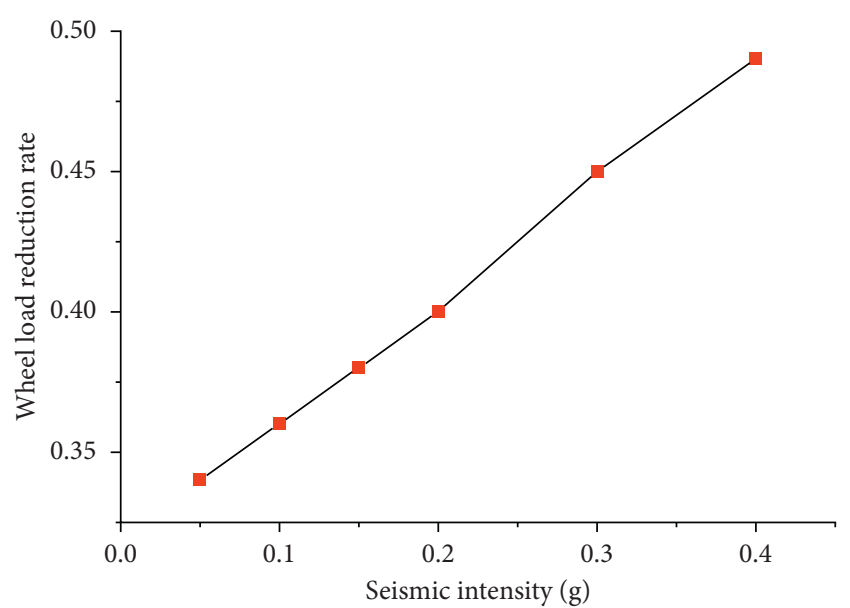

(d)

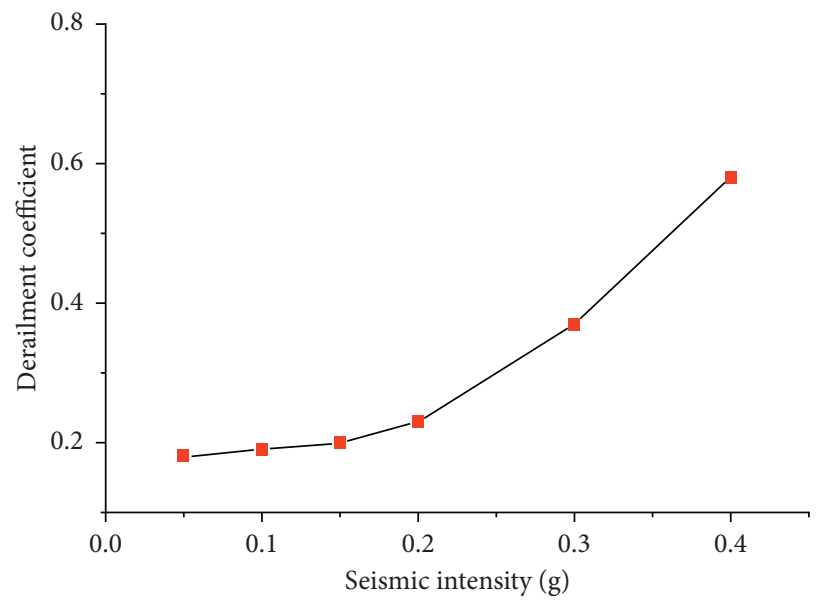

(e)

Figure 22: Changes in the dynamic response indexes under the El Centro wave. (a) Changes in lateral acceleration. (b) Changes in lateral force. (c) Changes in vertical force. (d) Changes in wheel load reduction rate. (e) Changes in derailment coefficient.

sudden and fatal damage to the wheel-track-subgrade system.

Under the action of the Taft wave, the lateral acceleration, wheel-rail lateral force, wheel-rail vertical force, wheel load reduction rate, and derailment coefficient change with respect to changes in the seismic intensities, as shown in Figure 23.

Under the action of the Taft wave, when the seismic intensity is $0.05 \sim 0.15 \mathrm{~g}$, as the seismic intensity increases, the lateral acceleration, wheel-rail lateral force, wheel-rail vertical force, wheel load reduction rate, and derailment coefficient all increase approximately linearly. When the seismic intensity is $0.15 \mathrm{~g}$, the train derails from the track, and the wheel load reduction rate is 1 . Therefore, when the seismic wave intensity is $0.15 \sim 0.4 \mathrm{~g}$, the specific values of the dynamic response indexes are not given.

Under the action of the Qian'an wave, the lateral acceleration, wheel-rail lateral force, wheel-rail vertical force, 


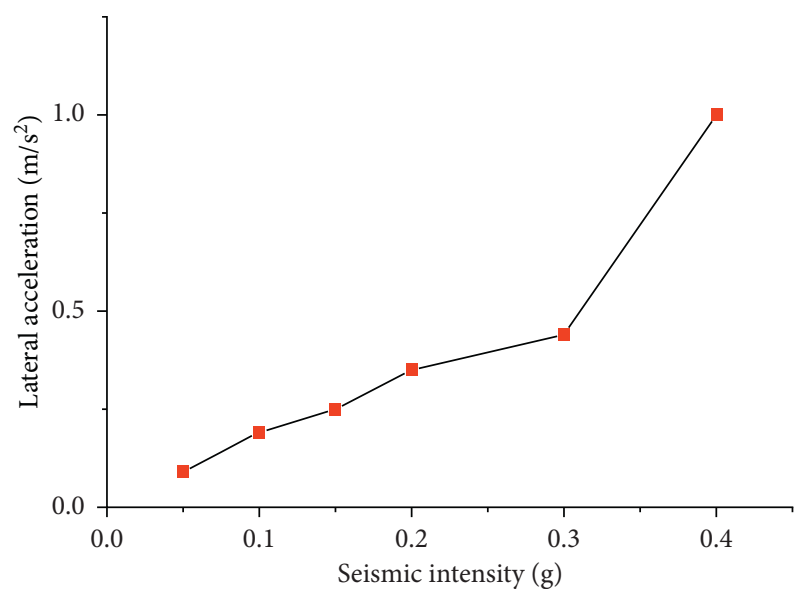

(a)

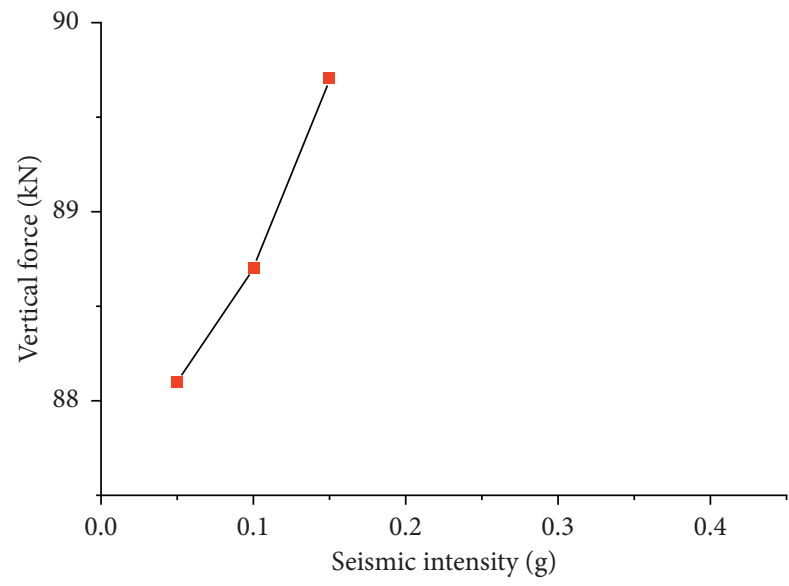

(c)

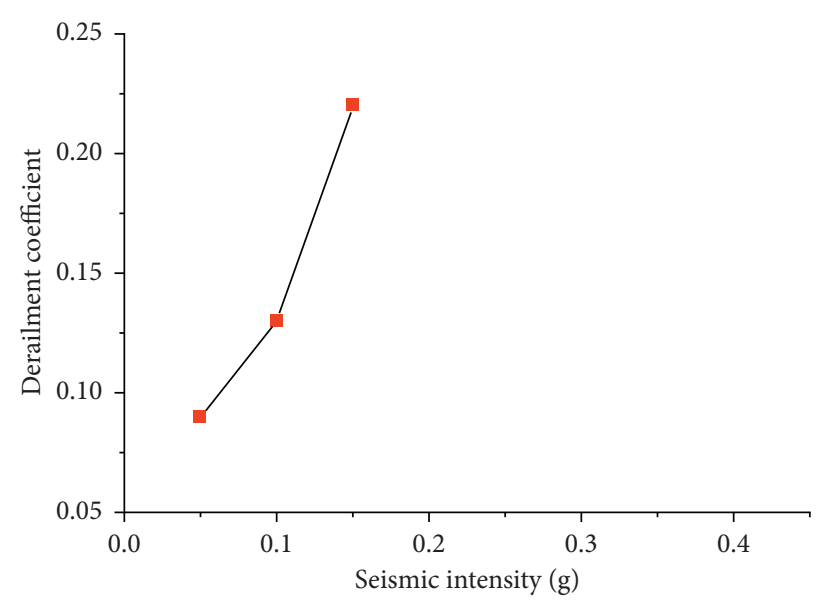

(e)

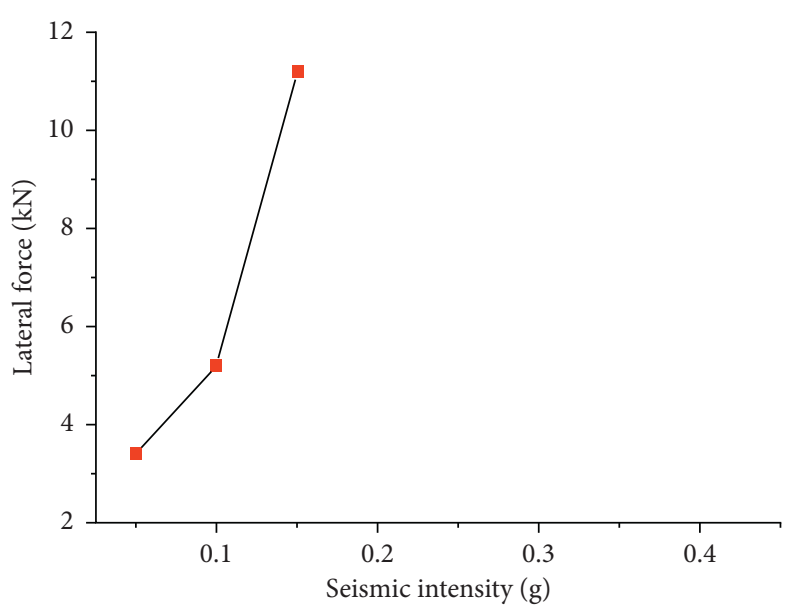

(b)

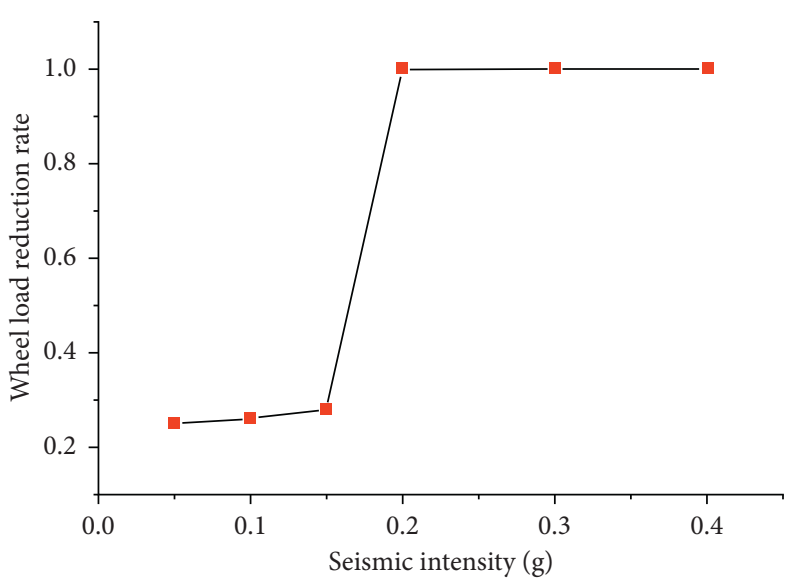

(d)

FIGURE 23: Changes in the dynamic response indexes under the Taft wave. (a) Changes in lateral acceleration. (b) Changes in lateral force. (c) Changes in vertical force. (d) Changes in wheel load reduction rate. (e) Changes in derailment coefficient.

wheel load reduction rate, and derailment coefficient change with respect to changes in the seismic intensity, as shown in Figure 24.
Under the action of the Qian'an wave, with increasing seismic intensity, the lateral acceleration, wheel-rail vertical force, and wheel load reduction rate increase approximately 


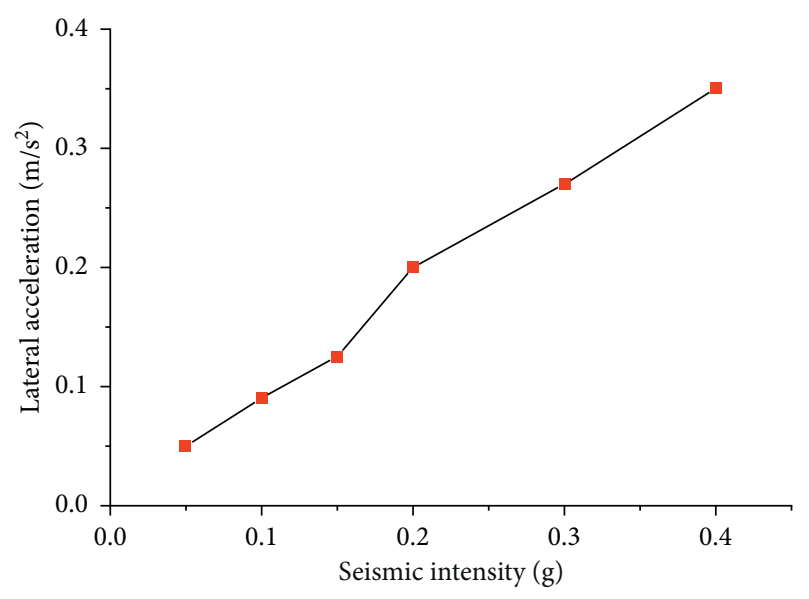

(a)

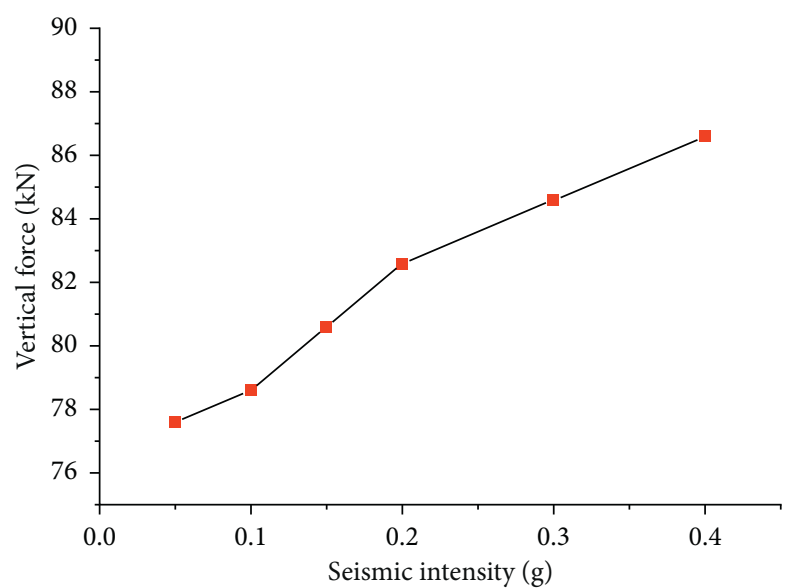

(c)

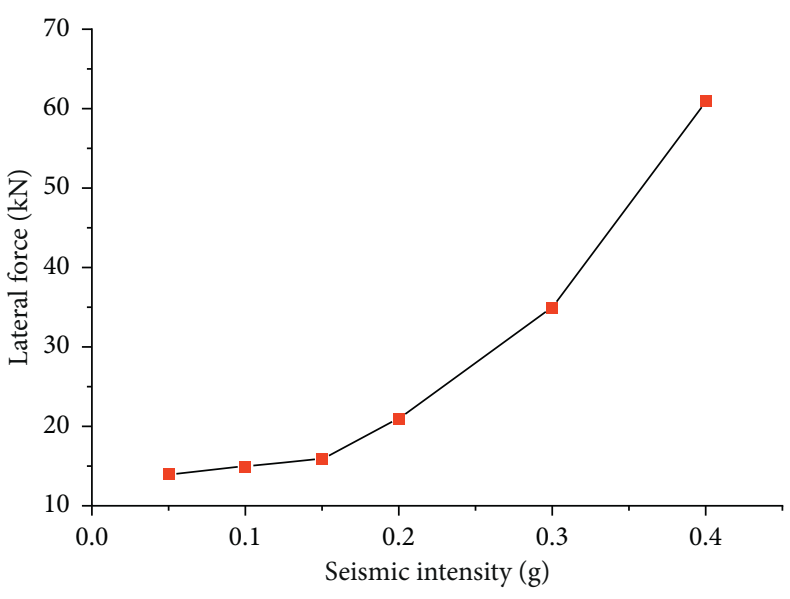

(b)

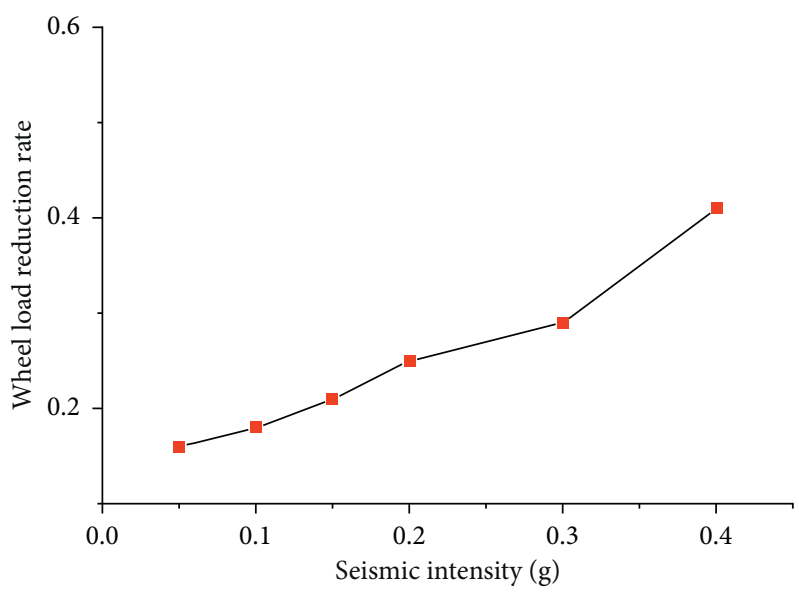

(d)

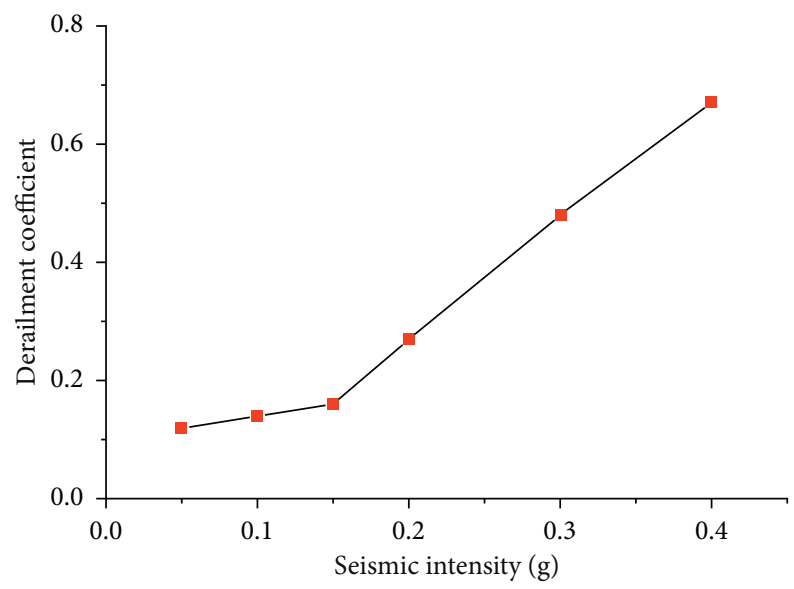

(e)

FIgURE 24: Changes in the dynamic response indexes under the Qian'an wave. (a) Changes in lateral acceleration. (b) Changes in lateral force. (c) Changes in vertical force. (d) Changes in wheel load reduction rate. (e) Changes in derailment coefficient. 
linearly. When the seismic wave intensity is $0.4 \mathrm{~g}$, the wheel load reduction rate is 0.41 , and the derailment coefficient is 0.67 , which has exceeded the limit of train running safety regulations. Hence, the train has not yet derailed but is on the verge of derailing.

\section{Conclusions}

In this paper, a wheel-track-subgrade dynamics model is proposed to study the influence of different seismic waves on the running safety of trains. The running safety of trains is analyzed according to the dynamic response indexes. A wheel-track-subgrade model is constructed using the finite element method, and the lateral acceleration, wheel-rail lateral force, wheel-rail vertical force, wheel load reduction rate, and derailment coefficient are studied under four types of seismic waves: the Tianjin wave, the El Centro wave, the Taft wave, and the Qian'an wave. The main conclusions are as follows:

(1) A numerical model of the wheel-track-subgrade system is established by the finite element method. The connection method between model components is proposed, and the viscoelastic artificial boundary is established.

(2) By normalizing the four types of seismic waves (the Tianjin wave, the El Centro wave, the Taft wave, and the Qian'an wave), the equivalent loads of the four seismic waves are obtained by considering only the lateral ground motion. By applying artificial boundaries, a finite element model seismic wave input method is proposed.

(3) The changing laws of different dynamic response indexes under the influence of the four seismic waveforms are studied. Under the action of the Tianjin wave, the wheel-rail dynamic response is extremely violent near the acceleration peak. After the peak value, the dynamic response is within a safe range. Under the action of the El Centro wave, the collision between the wheel and the rail is quite violent, and the train is already in a dangerous state. Under the action of the Taft wave, due to the sudden action of the peak acceleration of the seismic wave, the displacement between the wheel and the rail increases instantly, causing the train to derail. Under the action of the Qian'an wave, the force between the wheel and rail follows the frequency of the seismic wave, and all dynamic response indexes are within a safe range. The vibration intensity of the four seismic waves is amplified by the intensity expansion factor. In addition to the Tianjin wave, the amplified seismic wave has a greater impact on the running safety of the train.

\section{Data Availability}

The data used to support this study are available within the article.

\section{Conflicts of Interest}

The authors declare that there are no conflicts of interest regarding the publication of this paper.

\section{Acknowledgments}

This research was funded by National Natural Science Foundation of China (41772318) and Youth Innovation Team Talent Training Program of Shandong Province, China.

\section{References}

[1] Code for Seismic Design of Railway Engineering, Ministry of Railways of the People's Republic of China, Beijing, China, 2006.

[2] X. Wu, S. Liang, and M. Chi, "An investigation of rocking derailment of railway vehicles under the earthquake excitation," Engineering Failure Analysis, vol. 117, Article ID 104913, 2020.

[3] Y. Wang, B. Liu, and Y. Qi, "A risk evaluation method with an improved scale for tunnel engineering," Arabian Journal for Science and Engineering, vol. 43, no. 4, pp. 2053-2067, 2018.

[4] Y. Wang, J. Su, S. L. Zhang, S. Y. Guo, P. Zhang, and M. Q. Du, "A dynamic risk assessment method for deep-buried tunnels based on a Bayesian network," Geofluids, vol. 2020, Article ID 8848860, 14 pages, 2020.

[5] J. Sun, B. Liu, Z. Chu, L. Chen, and X. Li, "Tunnel collapse risk assessment based on multistate fuzzy Bayesian networks," Quality and Reliability Engineering International, vol. 34, no. 8, pp. 1646-1662, 2018.

[6] Y. Wang, Y. J. Zhang, Z. Zhu, M. Q. Du, and Y. Qi, “A novel method for analyzing the factors influencing ground settlement during shield tunnel construction in upper-soft and lower-hard fissured rock strata considering the coupled hydromechanical properties," Geofluids, vol. 2020, Article ID 6691157, 13 pages, 2020.

[7] K. Wu, Z. S. Shao, and S. Qin, "An analytical design method for ductile support structures in squeezing tunnels," Archives of Civil and Mechanical Engineering, vol. 20, p. 13, 2020.

[8] K. Wu, Z. Shao, S. Qin, W. Wei, and Z. Chu, "A critical review on the performance of yielding supports in squeezing tunnels," Tunnelling and Underground Space Technology, vol. 114, 2021.

[9] S. Miura, Deformation of Track and the Safety of Train in Earthquake, Vol. 37, Railway Technical Research Institute, Tokyo, Japan, 1996.

[10] T. Miyamoto, H. Ishida, and M. Matsuo, Running Safety of Railway Vehicle as Earthquake Occurs, Vol. 38, Railway Technical Research Institute, Tokyo, Japan, 1997.

[11] M. Kuzuta, K. Ueki, T. Miyamoto, Y. Nishiyama, and E. Maebashi, "Numerical dynamic simulation of a train set running on ballasted track after derailment," Quarterly Report of RTRI, vol. 54, no. 2, pp. 112-117, 2013.

[12] X. Luo, "Study on methodology for running safety assessment of trains in seismic design of railway structures," Soil Dynamics and Earthquake Engineering, vol. 25, no. 2, pp. 79-91, 2005.

[13] X. Luo and T. Miyamoto, "Method for running safety assessment of railway vehicles against structural vibration displacement during earthquakes," Quarterly Report of RTRI, vol. 48, no. 3, pp. 129-135, 2007. 
[14] Y. Guiping, X. He, and C. Yingjun, "Earthquake responses of the train and arch stiffened bridge system," Journal of Northern Jiaotong University, vol. 18, pp. 9-16, 1994.

[15] Z. Nan and X. He, "Influence of earthquake on running safety of vehicles on multi-span girders bridge," World Information on Earthquake Engineering, vol. 17, pp. 93-99, 2001.

[16] N. Zhang, H. Xia, and G. De Roeck, "Dynamic analysis of a train-bridge system under multi-support seismic excitations," Journal of Mechanical Science and Technology, vol. 24, no. 11, pp. 2181-2188, 2010

[17] C. Zhen, Research on Dynamic Response of High Speed Railway: Wuhan Institute of Rock and Soil Mechanics, The Chinese Acadamy of Science, Beijing, China, 2006.

[18] N. Zhihong, Study on Vertical Dynamic Response of the Track/ Subgrade in High-Speed Railway, Central South University, Changsha, China, 2005.

[19] W. Gong, Z. Zhu, K. Wang, W. Yang, Y. Bai, and J. Ren, “A real-time co-simulation solution for train-track-bridge interaction," Journal of Vibration and Control, Article ID 1077546320946631, 2020.

[20] X. Yang, H. Wang, and X. Jin, "Numerical analysis of a trainbridge system subjected to earthquake and running safety evaluation of moving train," Shock and Vibration, vol. 2016, Article ID 9027054, , 2016.

[21] Code for Design of Railway Earth Structure, National Railway Administration of the People's Republic of China, Beijing, China, 2016.

[22] L. Zhenpeng, "Numerical simulation of near-field fluctuations," Advances in Mechanics, vol. 27, pp. 50-71, 1997.

[23] L. Jingbo, W. Zhenyu, D. Xiuli, and D. Yixin, "Three-dimensional visco-elastic artificial boundaries in time domain for wave motion problems," Engineering Mechanics, vol. 22, pp. 46-51, 2005.

[24] J. Liu, Y. Du, X. Du, Z. Wang, and J. Wu, "3D viscous-spring artificial boundary in time domain," Earthquake Engineering and Engineering Vibration, vol. 5, no. 1, pp. 93-102, 2006.

[25] J. Liu, H. Tan, X. Bao, D. Wang, and S. Li, "Seismic wave input method for three-dimensional soil-structure dynamic interaction analysis based on the substructure of artificial boundaries," Earthquake Engineering and Engineering Vibration, vol. 18, no. 4, pp. 747-758, 2019.

[26] W. C. Young, R. G. Budynas, and A. M. Sadegh, Roark's Formulas for Stress and Strain, McGraw-Hill, New York, NY, USA, 2002.

[27] Z. Xiaoqing and C. Zhiyuan, "Application of semi-analytical numberical method to double-tube tunnel structures," Engineering Mechanics, vol. 15, pp. 3-5, 1998. 